\title{
Impacts of Gulf of Mexico SST Anomalies on Southern Plains Freezing Precipitation: ARW Sensitivity Study of the 28-30 January 2010 Winter Storm*
}

\author{
ESTHER D. MULLENS \\ Cooperative Institute for Mesoscale Meteorological Studies, and South Central Climate Science Center, \\ University of Oklahoma, Norman, Oklahoma \\ LANCE M. LESLIE \\ Cooperative Institute for Mesoscale Meteorological Studies, and School of Meteorology, \\ University of Oklahoma, Norman, Oklahoma \\ Peter J. LAMB \\ Cooperative Institute for Mesoscale Meteorological Studies, University of Oklahoma, Norman, Oklahoma
}

(Manuscript received 30 October 2014, in final form 28 September 2015)

\begin{abstract}
Ice storms are an infrequent but significant hazard in the U.S southern Great Plains. Common synoptic profiles for freezing precipitation reveal advection of low-level warm moist air from the Gulf of Mexico (GOM), above a shallow Arctic air mass ahead of a midlevel trough. Because the GOM is the proximal basin and major moisture source, this study investigates impacts of varying GOM sea surface temperature (SST) on the thermodynamic evolution of a winter storm that occurred during 28-30 January 2010, with particular emphasis on the modulation of freezing precipitation. A high-resolution, nested ARW sensitivity study with a 3.3-km inner domain is performed, using six representations of GOM SST, including control, climatological mean, uniform $\pm 2^{\circ} \mathrm{C}$ from control, and physically constrained upper- and lower-bound basin-average anomalies from a 30-yr dataset. The simulations reveal discernable impacts of SST on the warm-layer inversion, precipitation intensity, and low-level dynamics. Whereas total precipitation for the storm increased monotonically with SST, the freezing-precipitation response was more varied and nonlinear, with the greatest accumulation decreases occurring for the coolest SST perturbation, particularly at moderate precipitation rates. Enhanced precipitation and warm-layer intensity promoted by warmer SST were offset for the highest perturbations by deepening of the weak $850-\mathrm{hPa}$ low circulation and faster eastward progression associated with enhanced baroclinicity and diabatic generation of potential vorticity. Air-parcel trajectories terminating within the freezing-precipitation region were examined to identify airmass sources and modification. These results suggest that GOM SST can affect the severity of concurrent ice-storm events in the southern Great Plains, with warmer basin SST potentially exacerbating the risk of damaging ice accumulations.
\end{abstract}

\section{Introduction}

The southern Great Plains (SGP) of the United States is an area of diverse meteorological conditions. Winter months are typically mild (e.g., Johnson and Duchon

\footnotetext{
* Supplemental information related to this paper is available at the Journals Online website: http://dx.doi.org/10.1175/JAMC-D-14-0289.s1.

Corresponding author address: Esther D. Mullens, Suite 2100, 201 Stephenson Parkway, Norman, OK 73019.

E-mail: esther.white@ou.edu
}

1995), but the region is known for infrequent yet significant winter storms that produce mixed-phase precipitation, including snow, ice pellets, and freezing rain (e.g., Changnon 2003; Grout et al. 2012). Ice pellets and freezing rain are classically associated with an elevated above-freezing inversion ("warm layer"). In the presence of a moist air mass and forcing for ascent, frozen precipitation that encounters this layer can partially or completely melt, subsequently descending through a near-surface layer of freezing air ("refreezing layer"). When this refreezing layer is shallow and the warm layer is deep, precipitation remains in supercooled liquid form 
as freezing rain, whereas a cooler and deeper refreezing layer or shallow warm layer promotes partial melting and/ or refreezing of hydrometeors (e.g., Stewart and King 1987; Zerr 1997; Bernstein 2000; Robbins and Cortinas 2002). All phase types have detrimental impacts, but freezing rain is arguably of greatest concern because of the risk of ice loading on surface and elevated structures, such as power lines and tree limbs (Lackmann 2011b, p. 225). During 2000-10, the SGP experienced several major ice storms, defined by the National Weather Service (NWS) as freezing-rain accumulation exceeding $0.25 \mathrm{in} .(6.35 \mathrm{~mm})$ (e.g., Grout et al. 2012; Mullens 2014). Combined, these events resulted in over $\$ 1$ billion in damage, 35 directly attributable fatalities, and power disruption to over 3 million structures (estimated from the National Climatic Data Center Storm Event database; https://www.ncdc. noaa.gov/stormevents/). During this decade, Oklahoma led the United States in the number of winter-weatherrelated major federal disaster declarations, particularly for ice storms (Grout et al. 2012). Links between southern U.S. mixed-phase precipitation and large-scale atmospheric variability presently is unclear, with high interannual changes in frequency (e.g., Kunkel et al. 2013; Changnon and Karl 2003). Increased reliance of human socioeconomic and transport systems on electrical power compounds the disruption from recent events (Call 2009). Specific system evolutions, including moisture availability, duration, and warm-layer intensity also determine event magnitude.

For the SGP, freezing precipitation can occur north of a slow-moving cold front or a quasi-stationary front at the southern edge of a broad Arctic anticyclone (Sanders et al. 2013). The air mass south of the frontal zone typically is warm and moist maritime tropical air from the subtropics and Gulf of Mexico (GOM). Near the surface, cold- and/or dry-air advection and cloud cover aid in maintaining a shallow layer of subfreezing air (e.g., Lackmann 2011b, 210-211 and p. 225). The evolution of the height field, forcing for ascent, low-level mesoscale boundaries, precipitation processes, and location of subfreezing surface temperatures together control where and how much freezing precipitation may occur. Previous studies suggest that ice storms preferentially affect regions that are close to subtropical-origin maritime tropical air (Bernstein 2000; Changnon 2003; Changnon and Karl 2003). Lagrangian air-parcel trajectory studies by Gyakum and Roebber (2001) and Fuhrmann and Konrad (2013), for ice storms in the eastern United States, found that moisture availability and warm-layer development were associated with diabatic heating and moistening of air parcels in the subtropical Atlantic Ocean marine boundary layer, providing a physical connection between the ocean and warm-layer characteristics. Latent and sensible heat fluxes cause heat and moisture from the subtropical ocean to accumulate in the overlying air within the planetary boundary layer, as evidenced by additions of heat (as seen by increased temperature) and moisture into in situ air parcels. This modified air is subsequently lifted and advected into the winter storm, typically though a low-level jet or warm conveyor belt. Additions of heat and moisture into a midlatitude cyclone can serve to deepen the central pressure and intensify the system, with further feedbacks to precipitation amount and, in this case, phase. Only one prior modeling sensitivity study has directly investigated the role of sea surface temperature (SST) in moderating the timing and precipitation-phase partitioning in winter storms (Ramos da Silva et al. 2006). Atlantic Ocean SST was uniformly adjusted by $\pm 2^{\circ}$ and $\pm 4^{\circ} \mathrm{C}$ from a control simulation for heavy icing in western North Carolina. These idealized perturbations supported a relationship between SST and warm-layer intensity by indicating a warmer (cooler) inversion for increased (decreased) SST and earlier formation and increase of freezing rain relative to snowfall. Alterations to the locations of precipitation types and to the refreezing-layer temperatures were not identified.

This study evaluates the role of GOM SST in the evolution of freezing precipitation for the SGP. The basin has a known influence on regional meteorological behavior (e.g., Thompson and Burk 1993) and benefits from a common topographically forced low-level jet (e.g., Stensrud 1996), which rapidly advects moisture into the SGP in advance of midlevel troughs. Using the Advanced Research core (ARW) version 3.4 of the Weather and Forecasting (WRF) Model (e.g., Skamarock et al. 2008) in a high-resolution nested configuration, a set of SST perturbations is imposed on the GOM basin, and the thermal, moisture, and dynamical responses are examined, with particular emphasis on effects on icing severity and on perturbations to the behavior of the surface cyclone. Ensemble back-trajectory analysis is applied to each simulation to ascertain the origins of air parcels incident to the freezing-precipitation zone and their diabatic modification, particularly within the marine planetary boundary layer, as simulated by ARW. This study further assesses the results of Ramos da Silva et al. (2006) but for a different geographical region, and, to the authors' knowledge, the study is the first of its kind for the SGP. A range of perturbations are applied to ascertain the degree to which the evolving winter storm is sensitive to short-term antecedent and in situ anomalies, which may be important for numerical weather prediction of precipitation, for phase-type distribution, and in developing situational awareness. The case study is the multiphase winter storm of 28-30 January 2010. 
(a)

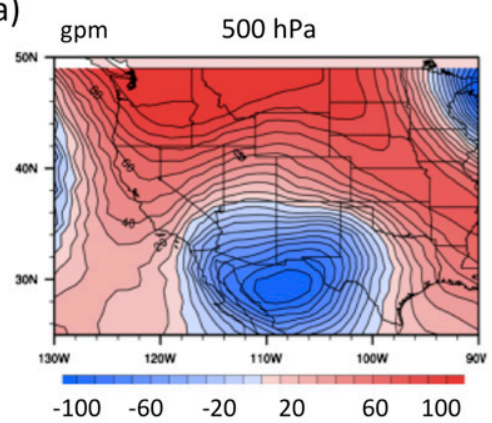

(d)

gpm 900-700 hPa Thickness

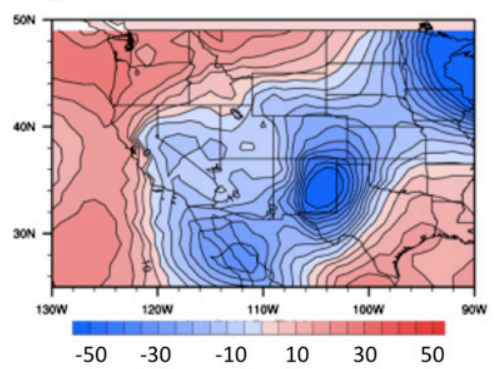

(b)

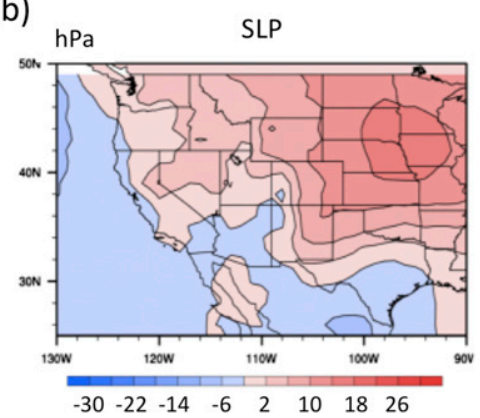

(e)

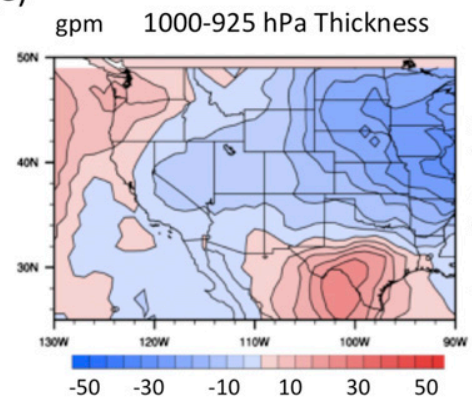

(c)

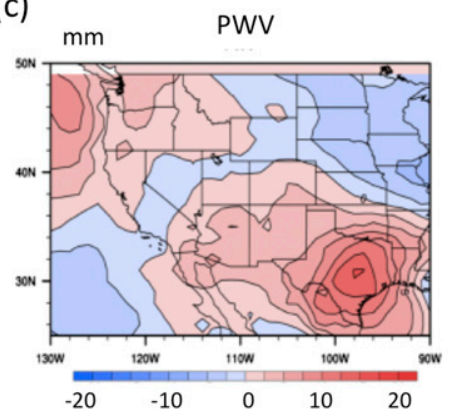

(f)

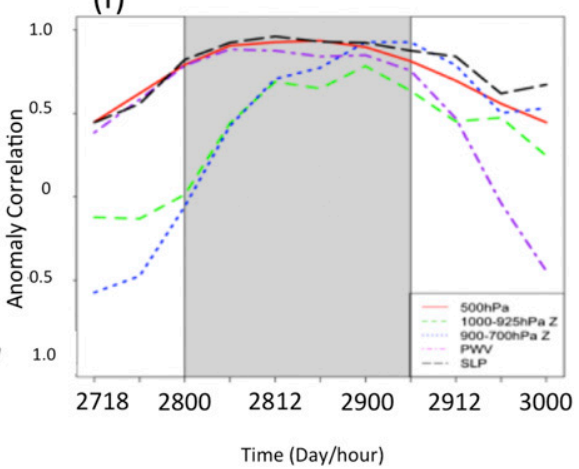

FIG. 1. Storm-average (for Oklahoma; 1200 UTC 28-29 Jan) composite anomaly fields from NARR $1^{\circ}$ grid spacing, using an NARR baseline climatological mean of 1979-2009: (a) 500-hPa geopotential height (m), (b) SLP (hPa), (c) precipitable water vapor (mm), (d) 900-700-hPa thickness (m), and (e) 1000-925-hPa thickness (m). (f) Anomaly correlations, calculated from Eq. (1), at 6-h intervals for 27-30 Jan 2010. Gray shading demarcates an approximate winter-storm duration for southwestern Oklahoma. The majority of freezing precipitation accumulated during 1200 UTC 28 Jan-0000 UTC 29 Jan.

Section 2 describes the storm event, SST perturbations, and model configuration. The performance of the control simulation is subsequently verified against observations, and key results of the sensitivity experiments are displayed. The paper concludes with a discussion of the main findings and their implications.

\section{Data and method}

\section{a. Case-study overview}

A severe winter storm affected a broad swath of the southern United States from 28 to 30 January 2010. Multiple precipitation phase types occurred over the SGP ahead of an amplified, positively tilted trough while a continental polar air mass extended over the central and eastern United States. The dynamical context is provided in Fig. 1, displaying storm mean anomalies in geopotential height, sea level pressure (SLP), moisture, lowlevel thickness, and near-surface thickness from North American Regional Reanalysis (NARR) data (Mesinger et al. 2006). Furthermore, the anomaly correlations (AC) in time, against anomaly features at 6-h intervals, were assessed as in Gyakum and Roebber (2001), using their Eq. (1):

$$
\mathrm{AC}=\frac{\sum_{i} \sum_{j} A_{i j} B_{i j}}{\left[\sum_{i} \sum_{j}\left(A_{i j}\right)^{2} \sum_{i} \sum_{j}\left(B_{i j}\right)^{2}\right]^{1 / 2}},
$$

where $A$ is the storm average anomaly field and $B$ is the instantaneous anomaly, with $A$ and $B$ being correlated over all grid points $(i, j)$. AC measures the persistence of features and therefore the system's temporal progression. Displayed anomalies show a midlevel low southwest of the SGP (Fig. 1a), high SLP throughout the plains bounded by a weak low pressure to the south (Fig. 1b), coupled with reduced thickness (1000-925 hPa; Fig. 1e), enhanced moisture over the south-central United States (Fig. 1c), and transitional positive-to-negative $700-900-\mathrm{hPa}$ thickness anomalies associated with the formation and movement of a warm layer and low-level cyclonic circulation (Fig. 1d). The event was progressive, as evidenced by AC decorrelation both prior to and after the main precipitation event over central Oklahoma.

Figures $2 \mathrm{a}-\mathrm{c}$ show $48-\mathrm{h}$ precipitation accumulation ending 0600 UTC 30 January, as based on stage-IV radar/ gauge analysis (NCEP 2000a). Phase types were separated using the "area method" algorithm of Bourgouin 

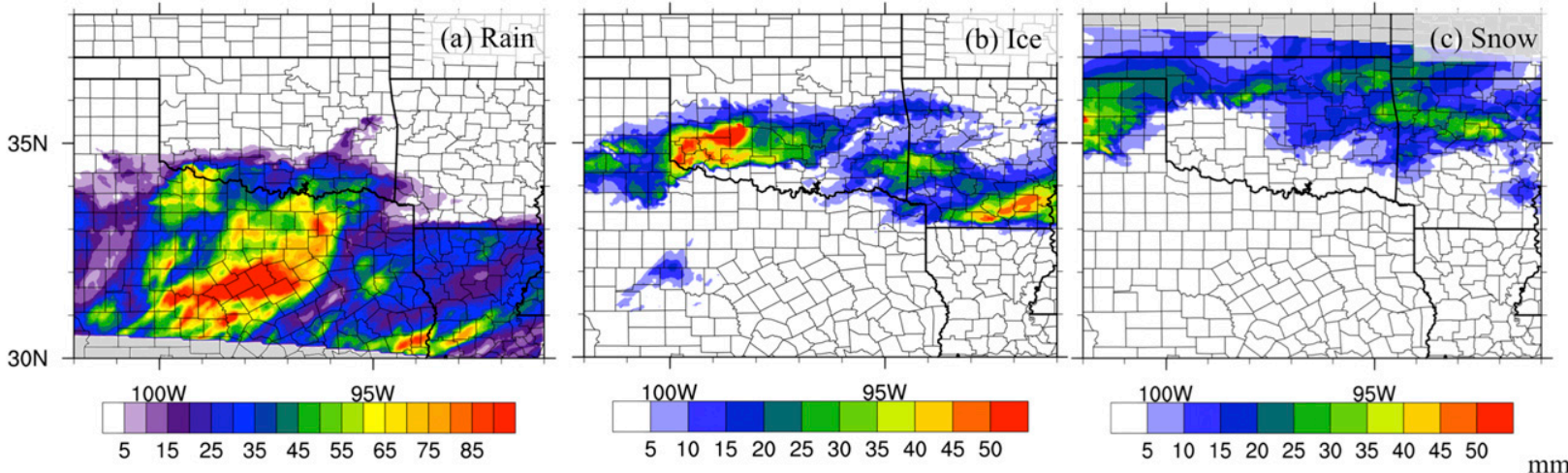

(d)

Temperature Time-Height (hours from 00 UTC Jan 23)

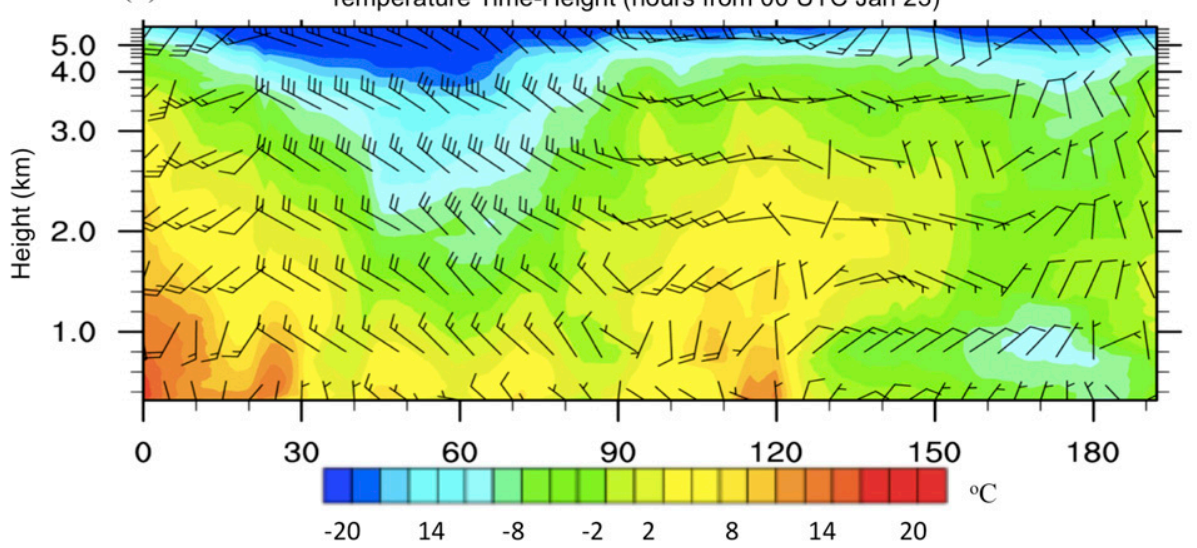

FIG. 2. The 48-h accumulated precipitation (mm; 1200 UTC 28 Jan-1200 UTC 30 Jan) for (a) rain, (b) ice, and (c) snow, as based on NCEP stage-IV data and phase partitioned using the Bourgouin (2000) area method and the ice definition provided in the text. Data are regridded to the latitude and longitude bounds of the ARW innermost nest [gray shading in (a) and (c) reflects locations that are external to this grid]. Temperature data are from the ARW CNTL simulation. Note the alternate color scheme/scale for rainfall in (a). (d) Timeheight profile of air temperature (shaded; ${ }^{\circ} \mathrm{C}$ ) and wind vectors (barbs) between the surface and $5 \mathrm{~km}$ from the ARM Merged Sounding Value-Added Product (http://www.arm.gov/data/vaps/mergesonde) at Lamont, Oklahoma, for 23-31 Jan.

(2000). An upper limit for freezing rain (hereinafter ice) is estimated by retaining algorithm-predicted freezing rain (FZRA), mixed freezing rain/ice pellets, and icepellet (IP) accumulations, the latter when the surface temperature $T$ was $-5^{\circ} \leq T \leq 0^{\circ} \mathrm{C}$. Below $-5^{\circ} \mathrm{C}$, there is increased likelihood of active ice nuclei and IP (e.g., Bernstein 2000; Cortinas et al. 2004), particularly in conjunction with a weak and/or elevated warm layer, which was not explicitly examined outside the algorithm. The "ice" definition also accounts for possible phase misclassifications, since complex microphysical processes governing melting, freezing, size distribution, and surface precipitation type are not fully accounted for by either the algorithm or the model microphysics. From NWS observations (e.g., http:// www.srh.noaa.gov/lub/?n=events-2010-20100128_snow; $\mathrm{http} / / / \mathrm{www}$. srh.noaa.gov/oun/?n=events-20100128), it is seen that ice accumulated along a swath extending from the Texas Panhandle to south-central Arkansas, with a maximum in southwestern Oklahoma, supporting the stage IV/algorithm-derived estimates (Fig. 2b). This region experienced up to $1.5 \mathrm{in}$. $(38.1 \mathrm{~mm})$ of freezing rain, approximately 180000 power outages statewide, and seven fatalities (Oklahoma Department of Emergency Management 2010). In addition to ice, heavy convective rainfall was observed over northern Texas and snowfall occurred from central and northern Oklahoma into northern Arkansas (Figs. 2a,c).

For the week encompassing this event, an in situ timeheight profile of the lower troposphere (Fig. 2d) showed strong northwesterly winds and cold-air intrusion over the SGP during 24-26 January. Southerly flow and warm surface temperatures were observed on 27 January in advance of the upper low, and subfreezing surface air advanced into the region early on 28 January. For southwestern and central Oklahoma, precipitation began as rainfall, in general after 1200 UTC, and made the transition to freezing rain by $1500 \mathrm{UTC}$, to ice pellets after 2100 UTC, and to snowfall over central Oklahoma after 0000 UTC 29 January (as based on the lead author's personal experience and on NWS summaries, which are not 
TABLE 1. SST-anomaly perturbations for the ARW sensitivity study. Each perturbation is named and defined, along with a brief description. The basin-average SSTA $\left({ }^{\circ} \mathrm{C}\right)$ is given relative to the $1981-2010$ climatological mean $(\mathrm{CLIM})$, and the control $(\mathrm{CNTL}$, in parentheses).

\begin{tabular}{llcl}
\hline \hline Simulation & \multicolumn{1}{c}{ Perturbation } & SSTA $\left({ }^{\circ} \mathrm{C}\right)$ Jan 2010 & \multicolumn{1}{c}{ Description } \\
\hline CNTL & None & $-0.85(0.0)$ & Actual SST field, daily (control) \\
CLIM & 1981-2010 average (daily) & $0.0(+0.85)$ & $1981-2010$ long-term average, daily \\
P2 & Uniform $+2 \mathrm{~K}$ & $+1.16(+2.0)$ & CNTL + 2, whole basin, daily \\
M2 & Uniform $-2 \mathrm{~K}$ & $-2.85(-2.0)$ & CNTL -2 , whole basin, daily \\
HI & Highest basin anomaly & $+0.83(+1.68)$ & Highest basin-mean SST from the 1981-2011 \\
& & & period for the week of 23-30 Jan \\
LO & Lowest basin anomaly & $-1.46(-0.61)$ & Lowest basin-mean SST from the 1981-2011 \\
& & & period for the week of 23-30 Jan \\
\hline
\end{tabular}

shown). Southern Arkansas experienced freezing rain and ice pellets in the 24-h period ending 060030 January. Precipitation was forced by strong ascent and advection of warm moist air east of the midlevel low, northeast of an 850-hPa cyclonic circulation, and north of a surface cold front over Texas.

\section{b. SST perturbations}

Here, a control and five idealized changes to basin SST were imposed, representing anomalously warm/ cool GOM scenarios, as summarized in Table 1. SST perturbations were applied over the GOM and the northern Caribbean Sea as resolved in ARW domain 1 (Fig. 3), including the Yucatan Channel and the Straits of Florida, consistent with the circulation that connects these regions. The control simulation (CNTL) uses the observed SST, and the CLIM simulation uses the 19812010 mean daily SST. The winter storm temporally coincided with a cool GOM; basin-average anomalies were $-0.85^{\circ} \mathrm{C}$ relative to CLIM, with strong negative anomalies particularly evident along the shallow Gulf coastal shelf (e.g., Fig. 14, described in more detail later). As in Ramos da Silva et al. (2006), uniform positive and negative $2^{\circ} \mathrm{C}$ changes (here designated $\mathrm{P} 2$ and M2, respectively) were imposed on CNTL. These four fields were obtained from the National Centers for Environmental Prediction Marine Modeling and Analysis Branch real-time, global, SST analysis (RTG_SST), at $0.5^{\circ}$ horizontal grid spacing and daily temporal resolution (http://polar.ncep.noaa.gov/sst/rtg_low_res/; accessed April 2013).

The P2 and M2 were the largest-magnitude perturbations used and are regarded as idealized. Therefore, two further perturbations were selected to represent realistic historical upper and lower bounds of present basin-average SST, as based on daily anomalies (SSTA) from the past $30 \mathrm{yr}$, valid for the dates of the winter storm. These anomalies were calculated with reference to the climatological mean and thus are more uniformly distributed around that metric (Table 1 and also Table 4, described in more detail below). Because of its longer temporal record, the latter fields were derived from the NOAA Optimal Interpolation, version 2 (OIv2, or OISST) (Reynolds et al. 2007; http://www.ncdc.noaa.gov/oisst), regridded from $0.25^{\circ}$ to $0.5^{\circ}$. Both RTG_SST and OIv2 use the same data sources (satellite and buoys) to evaluate SST, along with similar quality-control procedures, but $\mathrm{RTG}_{-}$ SST yields a smoother analysis. Differences between these two data sources are not considered to be detrimental to this study. The highest (lowest) basin-average SST fields on the basis of this work were denoted HI (LO). In all cases, the Pacific Ocean SST was fixed at its control value.

This experiment assumes that the atmosphere was not the primary driver of SST variability during the length of the model simulation and that a given winter storm has an approximately equal chance of occurring regardless of the SST distribution. Three fields (CNTL, M2, and P2) have the same basin distribution (albeit amplified), whereas CLIM, LO, and HI used alternate spatial fields.

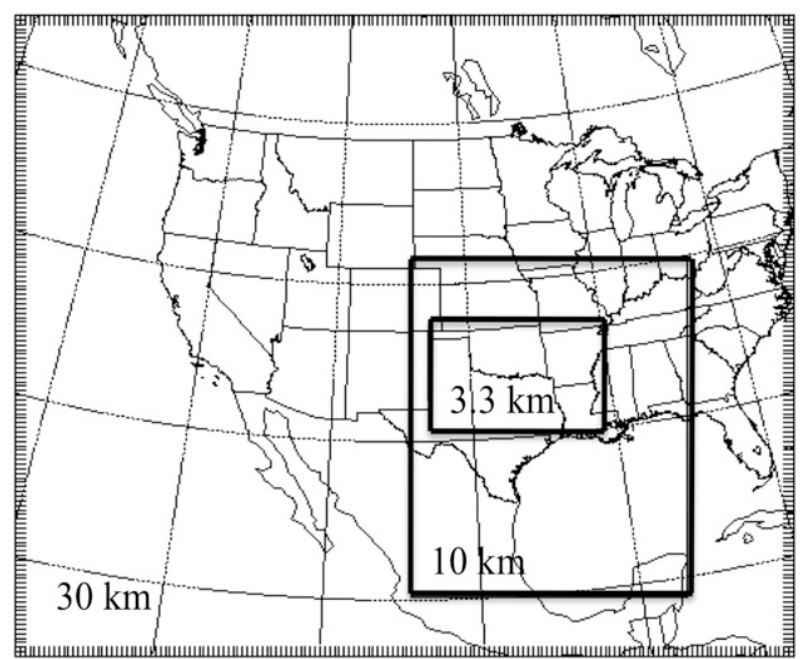

FIG. 3. ARW nested-domain configuration and horizontal grid spacing $(\mathrm{km})$. 
This approach allowed for some preliminary examination of the effects of subbasin GOM SST (sections 3 and 4). There may be a nontrivial role of gradients in the SST field on low-level thermal structure, wind fields, and cloud cover, with the most prominent gradient separating the coastal shelf from interior waters over the northern basin. This work primarily considers the impact of the broader SST distribution, however, since this is more likely to drive changes in the onshore thermal profile and freezing precipitation. Accounting for and representing the complex modes of variability in the GOM and Caribbean basin and their potential relationship to largescale atmospheric circulation were outside the scope of this work.

\section{c. ARW configuration}

ARW is a nonhydrostatic mesoscale model designed for operational and research applications. ARW has been used in previous winter-weather case-study research (e.g., Thompson et al. 2004; Holloway 2007; Bernadet et al. 2009; Shi et al. 2010; Hosek et al. 2011; Wang et al. 2011; Miller 2012; Gao et al. 2013), although ice-storm-modeling analyses appear infrequently in the literature. Here, a one-way nested configuration was used, allowing for high-resolution, explicitly resolved precipitation in the innermost domain. Three nests were employed, as shown in Fig. 3. The outermost nest (30-km horizontal grid spacing, hereinafter D1) covers the continental United States and eastern Pacific Ocean, which resolves synoptic-scale features and the GOM. The innermost nest (hereinafter D3; $3.3 \mathrm{~km}$ ) focuses on the area of freezing precipitation. For each, 59 staggered vertical levels were used, with 20 levels between the surface and the 0.8 eta level, designed to better resolve critical melting and refreezing layers. Input and boundary conditions (IP/BC) were from the $1^{\circ} \times 1^{\circ}$ NCEP GFS Final Analysis (FNL; NCEP 2000b) applied at 6-h intervals to D1. Perturbed SST fields were ingested by the ARW preprocessing software using the "METGRID" tool, which interpolates all IP/BC information to the model grid. SST was applied in addition to the GFS FNL at this stage and was updated every $24 \mathrm{~h}$, reflecting the dataset's daily resolution.

The choices of ARW physical parameterizations and other configuration specifics are shown in Table 2. The simulation of freezing precipitation was considered to be potentially sensitive to the planetary boundary layer (PBL) and microphysics (MP) schemes (e.g., Hosek et al. 2011). Combinations of two PBL [Yonsei University (YSU; Hong et al. 2006) and Mellor-Yamada-Janjić (MYJ; Mellor and Yamada 1982)] and four microphysics schemes [Thompson, WSM6 (Hong et al. 2006), Morrison, and Milbrandt-Yau] were used and evaluated against
TABLE 2. The ARW configuration, including physical parameterizations, input/boundary conditions, resolution, nudging, and start date/duration.

\begin{tabular}{|c|c|}
\hline Parameter & Description \\
\hline Start, length & 1200 UTC 23 Jan 2010, 7 days \\
\hline Temporal resolution & $3 \mathrm{~h}(\mathrm{D} 1) ; 2 \mathrm{~h}(\mathrm{D} 2) ; 0.5 \mathrm{~h}$ (D3) \\
\hline Domain, resolution & $\begin{array}{l}162 \times 141,30 \mathrm{~km}(\mathrm{D} 1) ; 172 \times 223,10 \mathrm{~km} \\
\quad(\mathrm{D} 2) ; 322 \times 223,3.3 \mathrm{~km}(\mathrm{D} 3)\end{array}$ \\
\hline Domain $x, y$ start & 1,1 (D1); 83, 14 (D2); 13, 110 (D3) \\
\hline Reference lat, lon & $36.6^{\circ},-105.0^{\circ}$ \\
\hline No. of vertical levels & 59 for D1-D3 \\
\hline Convection & BMJ for D1 and D2; explicit for D3 \\
\hline Microphysics & Millbrandt-Yau two moment for D1-D3 \\
\hline PBL & MYJ for D1-D3 \\
\hline Radiation & $\begin{array}{l}\text { RRTM (longwave) and Dudhia (short- } \\
\text { wave) for D1-D3 }\end{array}$ \\
\hline Land surface & Noah for D1-D3 \\
\hline $\mathrm{IP} / \mathrm{BC}$ & GFS Final Analysis ( $1^{\circ} ; 6$ hourly) \\
\hline Analysis nudging? & $\begin{array}{l}\text { Yes for D1 only: above eta level } 0.8 \text { for } \\
\text { temperature and mixing ratio and } \\
\text { above eta level } 0.95 \text { for wind; no for D2 } \\
\text { and D3 }\end{array}$ \\
\hline SST & $\begin{array}{l}\text { See Table } 1 \text { for descriptions; } 0.5^{\circ} \times 0.5^{\circ} \text {, } \\
\text { daily updates, RTG_SST (for CLIM, } \\
\text { P2, M2, and CNTL), and OIv2 (for LO } \\
\text { and } \mathrm{HI} \text { ) }\end{array}$ \\
\hline
\end{tabular}

observations to determine their suitability from an alternate case study (9-11 December 2007; not shown). The MYJ PBL was found to interact more realistically with the Betts-Miller-Janjić (BMJ) convective scheme (e.g., Lackmann 2011a), producing a more accurate surface temperature simulation. The local closure assumption of this PBL also tends to outperform the YSU scheme for stable boundary layers (Shin and Hong 2011). The Milbrandt-Yau two-moment MP scheme (Milbrandt and Yau 2005, 2006a,b; Milbrandt et al. 2010) explicitly treats seven hydrometeor classes (ice, cloud water, water vapor, snow, rain, graupel, and hail), predicting the number concentration and mixing ratios from a generalized gamma distribution. The scheme also allows the particle habits (shape parameter) to vary on the basis of a diagnostic relationship with the particle diameter, which can control excessive size sorting. This scheme, in conjunction with the MYJ PBL, generally outperformed the other microphysics evaluated with respect to precipitation location and intensity. Nonetheless, cross sections of snow, graupel, and rain mixing ratios for the January 2010 and alternate case (not shown) suggested that, even during situations of complete warm-layer melting in regions of observed freezing rain, surface graupel mixing ratios dominated over liquid rain. This may result from secondary ice production in the microphysics scheme overestimating partial refreezing. The Milbrandt-Yau parameterization of melting snow 
converts a portion of snow mass at each time step to rain, which can overestimate phase transitions below the melting layer (Milbrandt et al. 2014). This could contribute to different size distributions, thermal profiles, and precipitation type than are observed in situ. These limitations further support use of the algorithm-derived ice classification, as opposed to using microphysics to diagnose phase.

The model was initialized at 1200 UTC 23 January and was run for 7 days $(168 \mathrm{~h})$. The simulation length was chosen primarily to allow the model sufficient time to thermally adjust the lower troposphere to the SST. This temporal duration was also more than sufficient to damp any initial model "shock" resulting from the imposed SST fields (e.g., Semmler et al. 2008; Booth et al. 2012). The simulation length did require methods to constrain model uncertainty. Analysis nudging therefore was applied to D1 at 6-h intervals, and only above the lower troposphere (bottom 20 eta levels) for moisture and temperature. One-way nesting via the ARW "NDOWN" program was used to allow the inner two nests greater ability to vary in response to SST (e.g., Bond et al. 2010).

\section{d. Validation of control simulation}

CNTL was evaluated against observations, primarily for the innermost domain D3, to determine model efficacy at reproducing the evolution of the winter storm, focusing on low-level temperature and precipitation. Half-hourly surface air temperature observations were derived from 5-min Oklahoma Mesonet data (McPherson et al. 2007; Brock et al. 1995) across 120 stations, obtained from the Atmospheric Radiation Program central archive (http://archive.arm.gov/; accessed August 2012). Precipitation (all phases) was based on gridded gauge/radar product NCEP stage-IV data. Figure 4 and Table 3 show a subset of results pertaining to these variables. Table 3 shows verification and skill-score metrics calculated using the Model Evaluation Tools (MET; http://www.dtcenter.org/met/ users/) valid for 48-h accumulation (1200 UTC 28-30 January 2010). The 6-h time offset between this and the precipitation evaluated in Figs. 2, 5, 6, and 7 was unintentional but did not affect the consistency of the results, since almost all D3 precipitation occurred between 1200 UTC 28 January and 0600 UTC 30 January (not shown). Metrics were estimated using a neighborhood method encompassing a $5 \times 5$ gridpoint box for each observation ( $\sim 15-\mathrm{km}$ radius) with accumulation thresholds of $10,25,40$, and $60 \mathrm{~mm}$, representing approximately the 10 th percentile, the median, the 75 th percentile, and the 90th percentile (to the nearest $5 \mathrm{~mm}$ ) of the 48-h accumulated stage-IV precipitation, respectively.
An object-based method was also applied above $40 \mathrm{~mm}$ (Figs. 4a,b), in which the "object" is the spatial morphology of accumulated precipitation. The observed and simulated precipitation morphologies are then overlaid in space. Of note were the overestimated accumulations extending from northwest Texas into central Oklahoma (Fig. 4a) and the positive (wet) bias at 25 and $40 \mathrm{~mm}$ (Table 3). Discrimination of precipitation is better resolved above $25 \mathrm{~mm}$, and the object-based technique yields improved scores for accuracy, probability of detection below threshold (PODN), Heidke skill score (HSS), and Gilbert skill score (GSS) but little or no improvement in probability of detection at/above threshold (PODY), probability of false detection (POFD), and false-alarm ratio (FAR) and an increase in positive bias. The differing shapes of the precipitation regions likely produced this lack of substantial skill improvement from the object method. Overall, the ARW simulation is reliable with regard to the evolution of the event but misplaces the location(s) of greatest precipitation when compared with the stage-IV data. Total D3 accumulated precipitation was similar between model and observations, with a $2.6 \%$ decrease in the former (not shown), implying that available precipitable water was well constrained.

Figure $4 \mathrm{c}$ shows surface temperature and root-mean square error (RMSE) at 6-h intervals for Oklahoma, as based on a comparison with ARW (2 m) and Oklahoma Mesonet data $(1.5 \mathrm{~m})$. In this case, modeled surface temperatures tended to be lower than observed, especially from 0000 to 1200 UTC 28 January. The initially larger RMSE indicates that the ARW may have overestimated cooling over Oklahoma. Reasons for this do not appear to be related to cloud cover, but initially higher sea level pressure (not shown) may reflect more rapid advance of Arctic air, promoting a cooler surface. Nonetheless, the RMSE remained low, typically less than $2.5^{\circ} \mathrm{C}$. Vertical thermal profiles (temperature and mixing ratio) were also assessed during the storm using Atmospheric Radiation Measurement (ARM) Climate Research Facility Climate Modeling Best Estimate (CMBE, version 2; https://www.arm.gov/data/pi/36; accessed August 2012) sounding data (S. Xie et al. 2010). Missing observations precluded comparisons between 0000 and 1200 UTC 29 January, and the ARM site was located north of the freezing-rain region. The timing of a weak warm-layer inversion in the model preceded the observations, but substantial errors were not identified. Mixing ratios were in good agreement (within $1 \mathrm{~g} \mathrm{~kg}^{-1}$ ), with some timing offsets and slightly higher simulated low-level moisture. Model-observation differences at a given time potentially resulted from displacement in cloud and precipitation location, with resulting effects 


\section{Observation}

(a)

(b)

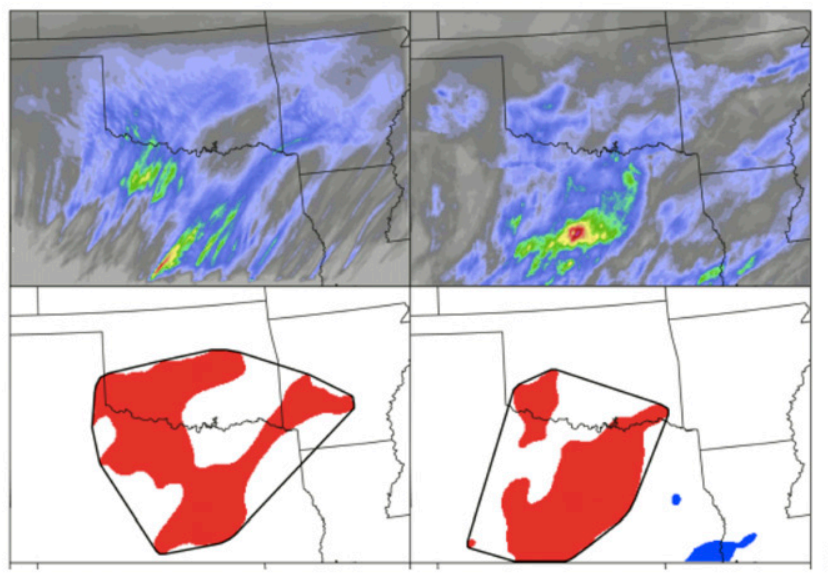

(c)

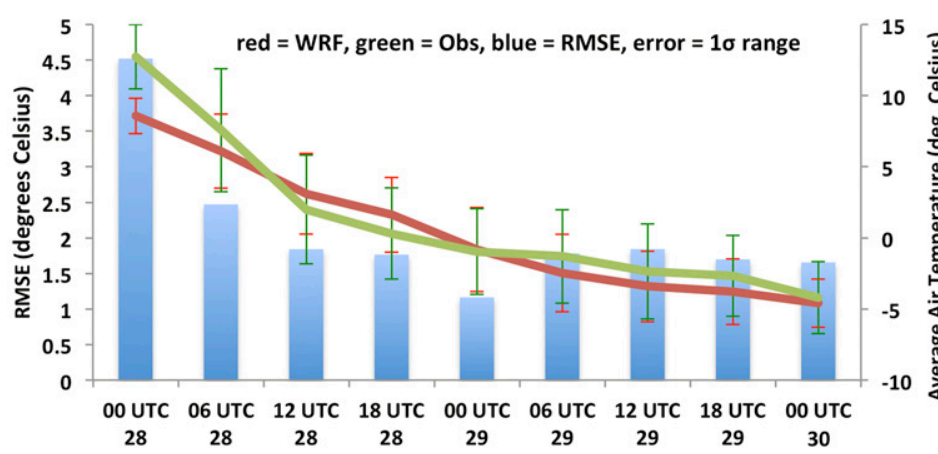

$(\mathrm{mm})$

FIG. 4. (a) The 48-h storm accumulated (left) ARW precipitation (D3; mm) and (right) stage-IV precipitation (mm). (b) Morphology of accumulation $\geq 40 \mathrm{~mm}$ (red shading) for (left) ARW control and (right) stage IV derived from MET, version 3.1. (c) Model (red line) and observed (green line) surface temperature evolution $\left({ }^{\circ} \mathrm{C}\right)$ derived from Oklahoma Mesonet observations and averaged over 30 point locations over Oklahoma. RMSE $\left({ }^{\circ} \mathrm{C}\right)$ is shown by the blue columns, also at 6 -h intervals. Error bars reflect 1 std dev about the mean.

on the thermal profile. From the same dataset, small [in general, $<5 \mathrm{kt}\left(1 \mathrm{kt} \approx 0.51 \mathrm{~m} \mathrm{~s}^{-1}\right)$ ] differences were identified for meridional and zonal flow, and the synoptic-height and wind fields agreed well with NARR (not shown). From this validation, the simulated winter storm reasonably replicated the actual event, lending confidence to its representation of important system processes, including warm-layer development and erosion, timing of subfreezing air, forcing for ascent and precipitation, and movement of attendant circulation. Well-simulated mesoscale features included development of a convective line over Texas and associated thermal and wind perturbations, including weakening of the warm layer. Model-overestimated precipitation for much of Oklahoma may have been associated with the persistence of precipitation early on 29 January, whereas radar observations indicated dry-air intrusion aloft and cessation of precipitation (not shown).

\section{Results}

\section{a. Accumulated precipitation}

Storm 48-h accumulated liquid precipitation equivalent and differences from CNTL are shown for each perturbed-SST simulation in Figs. 5, 6, and 7 for ice, snow, and rainfall, respectively. CNTL (Figs. 5d, 6d, and 7d) can be compared with the stage-IV phase-delineated accumulation in Figs. 2a-c. Differences in peak magnitude were apparent for each phase, albeit the simulated spatial distribution and intensity (particularly ice in Oklahoma) were similar to stage-IV estimates. Changes in both magnitude and location of precipitation with SST were indicated. For ice (Fig. 5), cooler SST generally produced a southward displacement and lower total accumulations, especially in the M2 simulation (Fig. 5c). CLIM (Fig. 5a), with a warmer basin SST than that in CNTL (see Table 1), showed intensified precipitation 
TABLE 3. Skill scores for different metrics as based on thresholds of 25 (median of observed distribution), 40 (upper quartile), and 60 (90th percentile) $\mathrm{mm}$ for 48-h accumulated total precipitation at 1200 UTC 28 Jan-30 Jan 2010. The observations are taken from the NCEP stage-IV 4-km gauge/radar-derived precipitation. A neighborhood of $5 \times 5$ grid points is used to calculate scores for the three thresholds, with a further estimate that is based on overlaying precipitation distribution "objects," as shown in Fig. 4b. The perfect value for each score is shown in the last column. All skill scores are calculated using MET, version 3.1. The dash indicates that the value was not calculated.

\begin{tabular}{lccccc}
\hline \hline Metric & $\geq 25 \mathrm{~mm}$ & $\geq 40 \mathrm{~mm}$ & $\geq 60 \mathrm{~mm}$ & Object; $\geq 40 \mathrm{~mm}$ & Perfect value \\
\hline Accuracy & 0.62 & 0.71 & 0.90 & 0.81 & 1.24 \\
Bias & 1.08 & 1.13 & 0.91 & 0.48 & 1 \\
PODY & 0.70 & 0.48 & 0.35 & 0.87 & 1 \\
PODN & 0.51 & 0.79 & 0.95 & 0.13 & 0.61 \\
POFD & 0.49 & 0.21 & 0.05 & 0.27 & 0 \\
FAR & 0.35 & 0.57 & 0.62 & 0.19 & 1 \\
CSI & 0.51 & 0.29 & 0.23 & 0.32 & 1 \\
GSS & 0.12 & 0.15 & 0.31 & - & 1 \\
HSS & 0.21 & 0.27 & 0.43 & &
\end{tabular}

for southwestern Oklahoma, whereas HI (Fig. 5e) and P2 (Fig. 5f) shifted precipitation maxima northeast into central Oklahoma and northward in Arkansas. The most discernable change in snowfall (Fig. 6) was a northward shift in the snow line with warmer SST, which is particularly evident from a comparison of M2 (Fig. 6c) and P2 (Fig. 6f). Differences in accumulations were most pronounced over Arkansas and diminished with lower-magnitude changes in SST. Rainfall (Fig. 7) revealed a northeastward broadening of heavy precipitation and some reduction to the south with warmer SST, implying a potential change in moisture distribution and thermodynamic profile, the latter promoting the farther-northward extent of above-freezing temperatures.

Table 4 shows quantitative changes relative to CNTL (and to CLIM for HI and LO) for all precipitation and for ice (in parentheses). The nonlinearity
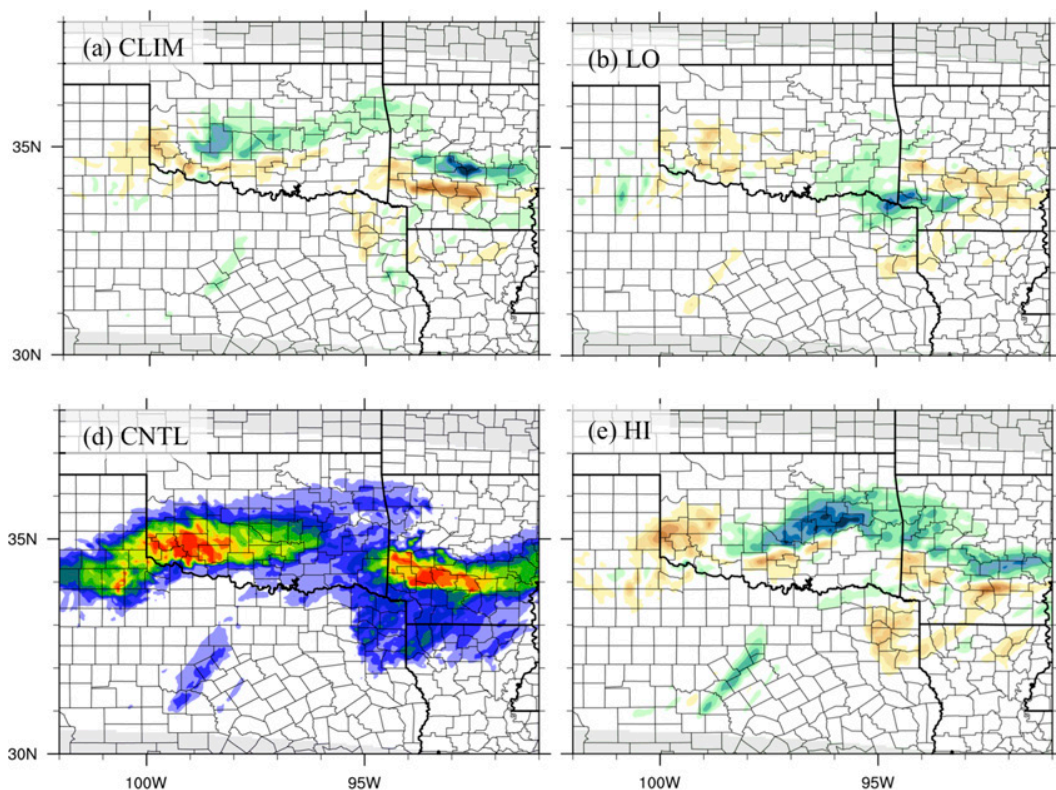

95W
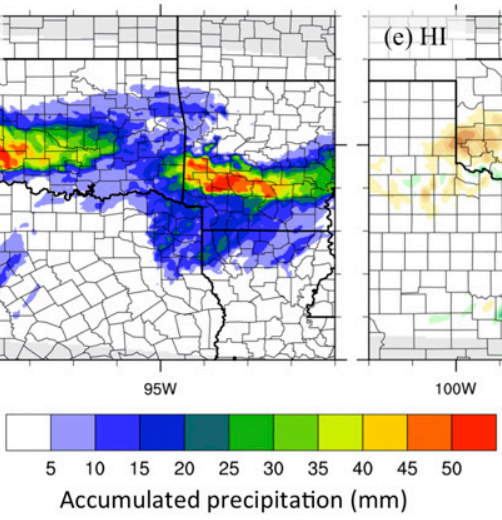
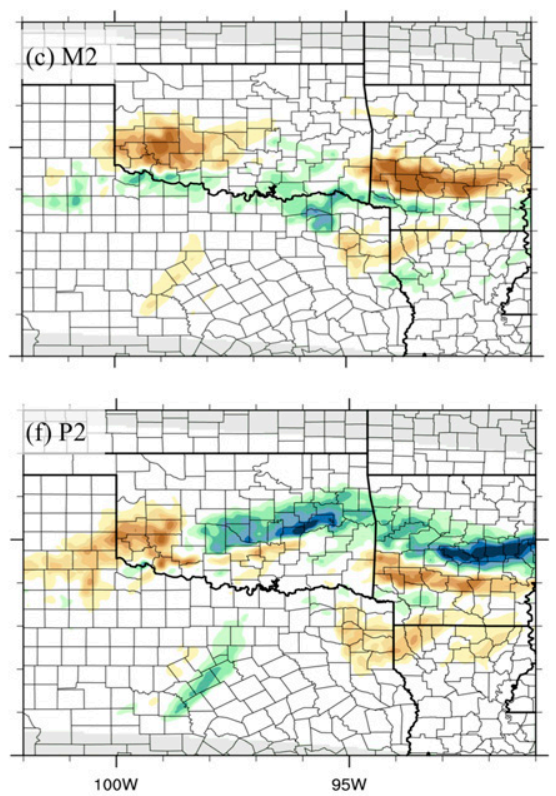

$95 \mathrm{~W}$

95W

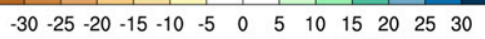

Accumulated precipitation - CNTL (mm)

FIG. 5. The 48-h storm accumulated freezing precipitation (D3; mm), derived from the Bourgouin (2000) ice assumption. (d) CNTL: full precipitation; (a)-(c), (e), (f) departures from CNTL for each SST-perturbed simulation. County and state boundaries are overlaid to aid location interpretation. Gray shading demarks the boundary of the model grid. 


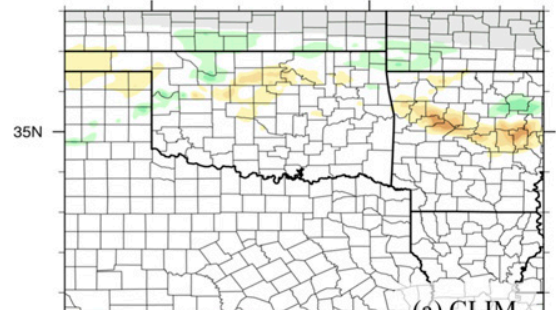

(a) CLIM

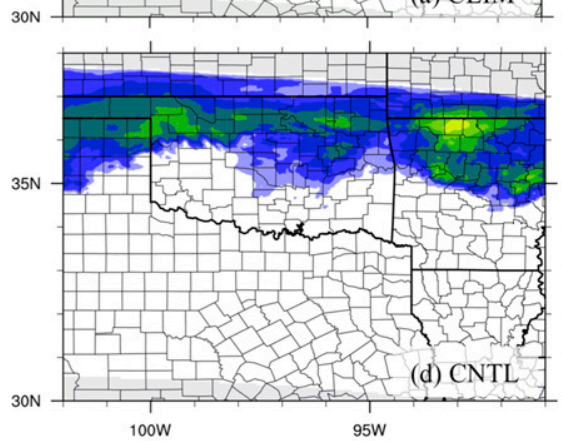

100W
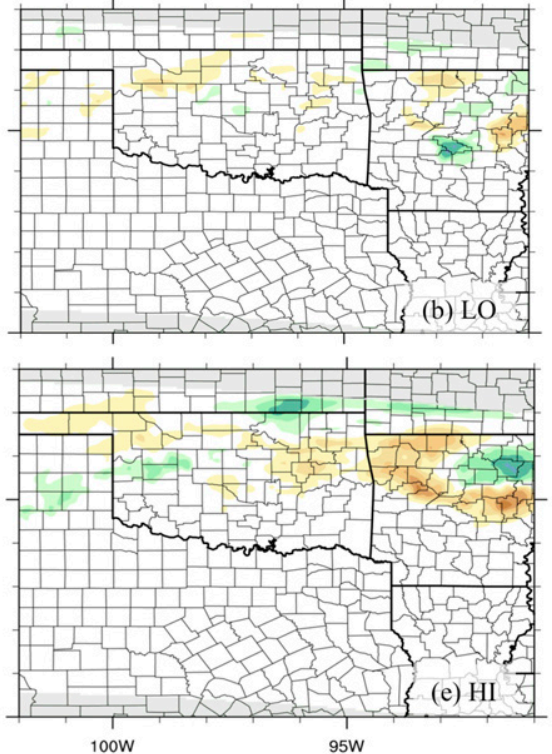

$95 \mathrm{~W}$
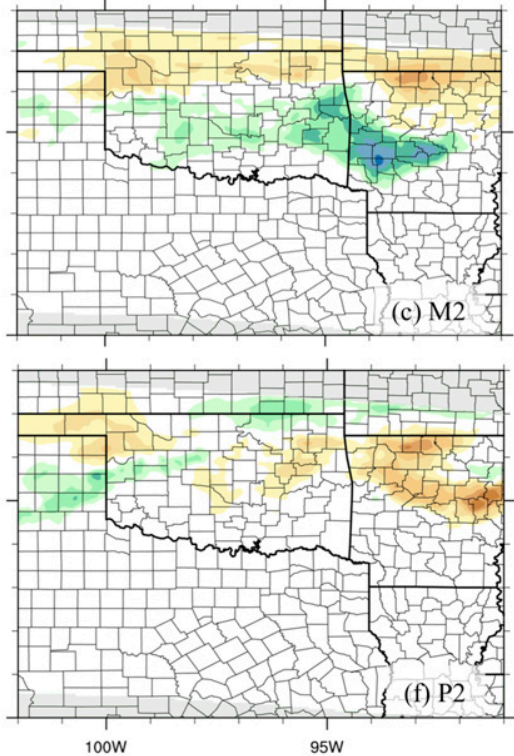
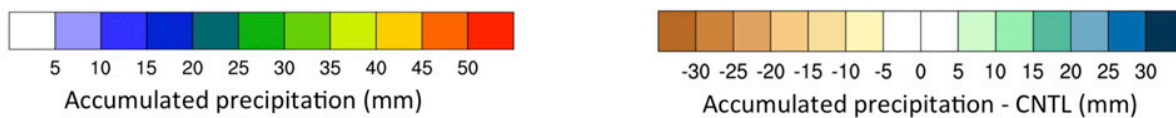

FIG. 6. As in Fig. 5, but for snowfall (shaded; mm), assuming that no warm layer is present and that surface temperature $\leq 0^{\circ} \mathrm{C}$.

of the precipitation response is evident, including generally greater sensitivity to strongly negative SST anomalies (M2) and larger percentage changes at higher precipitation thresholds. For example, relative to CNTL, M2 showed a near 39\% decrease in freezingprecipitation rates above $2.5 \mathrm{~mm} \mathrm{~h}^{-1}$, the defined threshold for moderate or greater precipitation. The spatial response for this phase type was smaller $(-10 \%$; 75 th percentile). In comparison, P2 yielded increases of $\sim 5 \%$ and $15 \%$, respectively. Percentage changes for CLIM and HI exceeded P2 for moderate or greater ice precipitation rates. Figure 5 demonstrated increased precipitation in CLIM and HI that generally exceeded decreases to the south. For P2, the decreased ice in southwestern Oklahoma was more pronounced (Fig. 5f) and may have offset increases to the east over the state. Run LO showed generally small changes in ice and, in some metrics an increase (e.g., distribution of ice $\geq 75$ th percentile: $+10 \%$ ). In comparison with CLIM, LO did indicate weakened precipitation rates and spatial extent (e.g., $-18 \%$ for total and $-16 \%$ for ice $>2.5 \mathrm{~mm} \mathrm{~h}^{-1}$ ), exceeding the magnitude of the increase from HI $(+2 \%$ for total and $+5 \%$ for ice). Simulated radar reflectivity (not shown) indicates potential changes in updraft strength in convection associated with this system and increased spatial extent and eastward progression of precipitation as SST increased.

\section{b. Warm-layer intensity}

The response of the melting- and refreezing-layer characteristics for this case study were examined using a metric defined in Robbins and Cortinas (2002) that quantifies the integrated potential for hydrometeor melting (refreezing), termed environmental melting (freezing) potential, or EMP (EFP):

$$
\begin{aligned}
& \mathrm{EMP}=\int_{\mathrm{zm}_{\text {bot }}}^{\mathrm{zm}_{\mathrm{top}}}\left(T_{0}-T_{w}\right) d z \text { and } \\
& \mathrm{EFP}=\int_{\mathrm{zf}_{\mathrm{bot}}}^{\mathrm{zf}_{\mathrm{top}}}\left(T_{0}-T_{w}\right) d z,
\end{aligned}
$$

where $T_{0}$ is $0^{\circ} \mathrm{C}, T_{w}$ is the wet-bulb temperature $\left({ }^{\circ} \mathrm{C}\right)$, and $\mathrm{zm}_{\text {top }}$ and $\mathrm{zm}_{\text {bot }}$ are the top and bottom of the above-freezing layer(s), respectively. The limit zf confers equivalent reasoning, but for the near-surface subfreezing layer. A warmer and deeper warm layer produces increased EMP, whereas deeper, cooler freezing layers increase EFP. Time series of EMP and EFP are shown for a subdomain of southwestern Oklahoma in Fig. 8 and western Arkansas in Fig. 9, corresponding to subregions of the two ice maxima in ARW (Fig. 5d). Three-hourly precipitation rates are also displayed. It is assumed that when EMP and EFP exceed $0^{\circ} \mathrm{C}$ concurrently and EMP is greater than EFP (red shaded) then freezing rain is likely, whereas when EFP is 

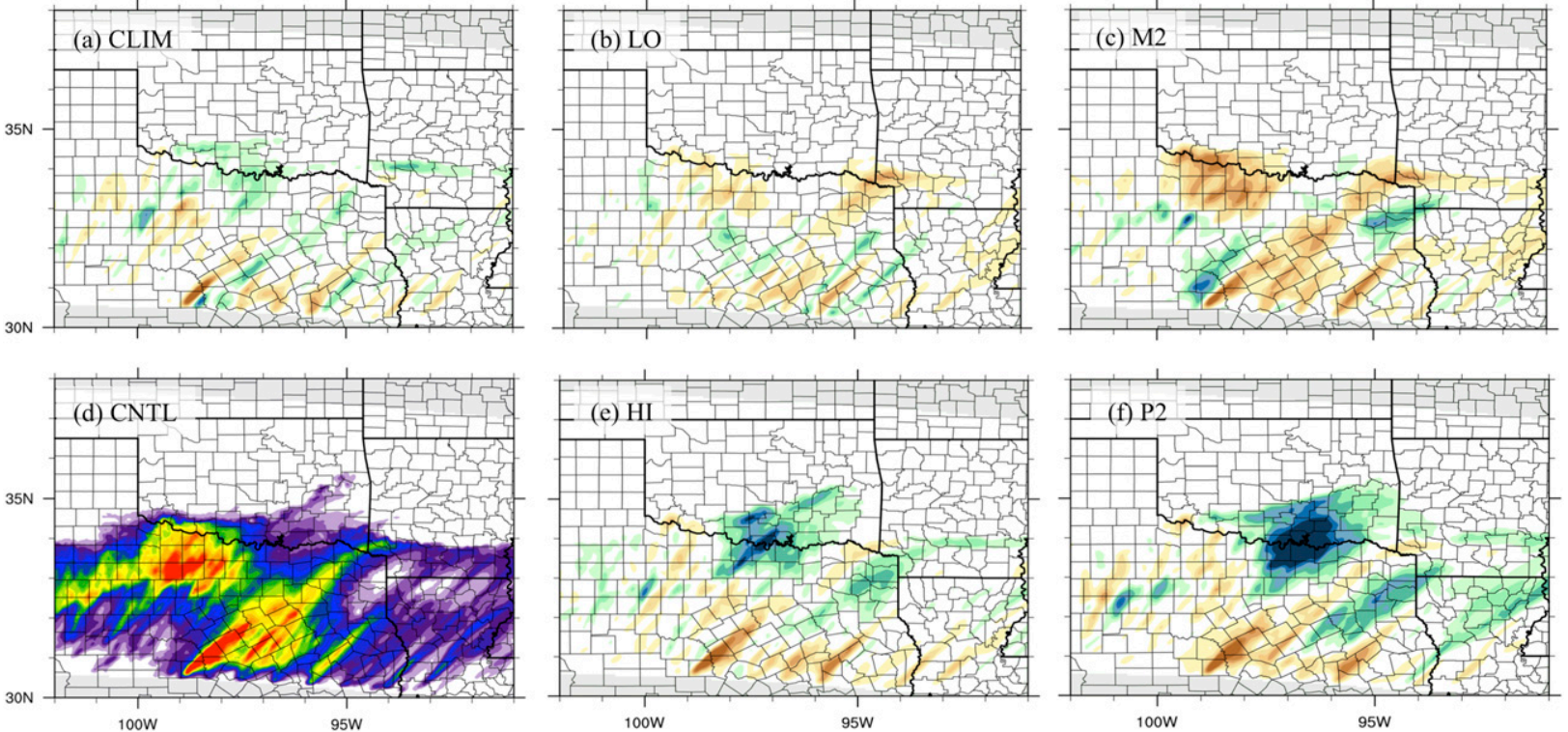
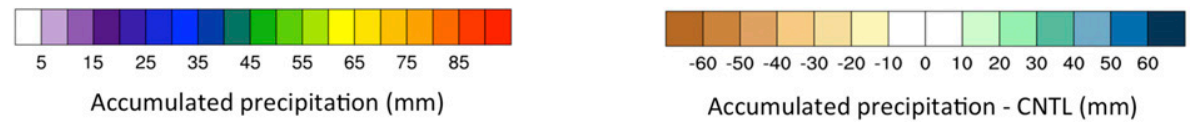

FIG. 7. As in Fig. 5, but for rainfall (shaded; mm), assuming that surface temperature $\geq 0.5^{\circ} \mathrm{C}$. Note that the two scales differ from those in Figs. 5 and 6.

greater than EMP (blue shaded) it indicates a cooler inversion and greater ice-pellet potential. For all simulations, the period between time $t=12$ and $t=20(1200$ 2000 UTC 28 January) for Fig. 8 was marked by EMP gradually decreasing from $6000^{\circ} \mathrm{C} \mathrm{m}$. For CNTL (Fig. 8d), LO (Fig. 8b), and M2 (Fig. 8c), the warm layer was eroded near $t=22-24$ (from 2200 UTC 28 January to 0000 UTC 29 January). This temporally coincided with maxima in precipitation rate for all scenarios except perhaps $\mathrm{M} 2$ where precipitation was light $\left(<2 \mathrm{~mm} \mathrm{~h}^{-1}\right)$. This likely reflects pronounced cooling in association with strong ascent, as well as the melting of precipitation (e.g., Kain et al. 2000), with the possible further contribution of evaporative cooling. With M2, the warm layer did not recover until $t=30$ (0600 UTC 29 January) and remained weak until its removal near $t=40$ (1600 UTC 29 January). The LO and CNTL simulations were similar in their evolution. CLIM (Fig. 8a), HI (Fig. 8e), and P2 (Fig. 8f) showed a warm layer that persisted until between $t=36$ and $t=40$ (1200-1600 UTC 29 January), with CLIM and HI visually supporting the highest and most persistent EMP for this duration. The P2 run showed

TABLE 4. Changes (\%)in precipitation accumulations for each SST simulation at the thresholds specified in the header row for all of D3 (first value in each cell) and for the freezing-precipitation region (i.e., ice; given in parentheses). The departures are given relative to CNTL and also to the climatological mean (CLIM) for HI and LO, since these latter perturbations are more evenly distributed about the climatological mean (Table 1). Departures $\geq|25 \%|$ are set in boldface font. Dashes indicate missing or nonapplicable information. The 75 th percentile $=42 \mathrm{~mm}$ for all of D3 and $16 \mathrm{~mm}$ for ice (stage IV).

\begin{tabular}{|c|c|c|c|c|c|c|}
\hline & \multicolumn{2}{|c|}{ No. of grid points $>75$ th percentile } & \multicolumn{2}{|c|}{ Total sum of hourly precipitation } & \multicolumn{2}{|c|}{$2.5 \mathrm{~mm} \mathrm{~h}^{-1}$} \\
\hline & CNTL & CLIM & CNTL & CLIM & CNTL & CLIM \\
\hline CLIM & $+5.6(+12.6)$ & - & $+2.1(+8.5)$ & - & $+4.3(+10.2)$ & - \\
\hline $\mathrm{P} 2$ & $+32.7(+14.5)$ & - & $+7.3(+1.0)$ & - & $+11.1(+5.3)$ & - \\
\hline M2 & $\mathbf{- 2 8 . 7}(-10.1)$ & - & $-16.5(-15.5)$ & - & $-29.9(-38.5)$ & - \\
\hline $\mathrm{HI}$ & $+20.5(+15.0)$ & $+14.9(+2.4)$ & $+4.1(+9.7)$ & $+2.0(-1.2)$ & $+6.2(+15.3)$ & $+1.9(+5.1)$ \\
\hline LO & $-18.7(+9.8)$ & $-24.3(-2.8)$ & $-7.5(-0.5)$ & $-9.6(-9.0)$ & $-13.2(-5.4)$ & $-17.5(-15.6)$ \\
\hline
\end{tabular}




\section{Southwestern Oklahoma}
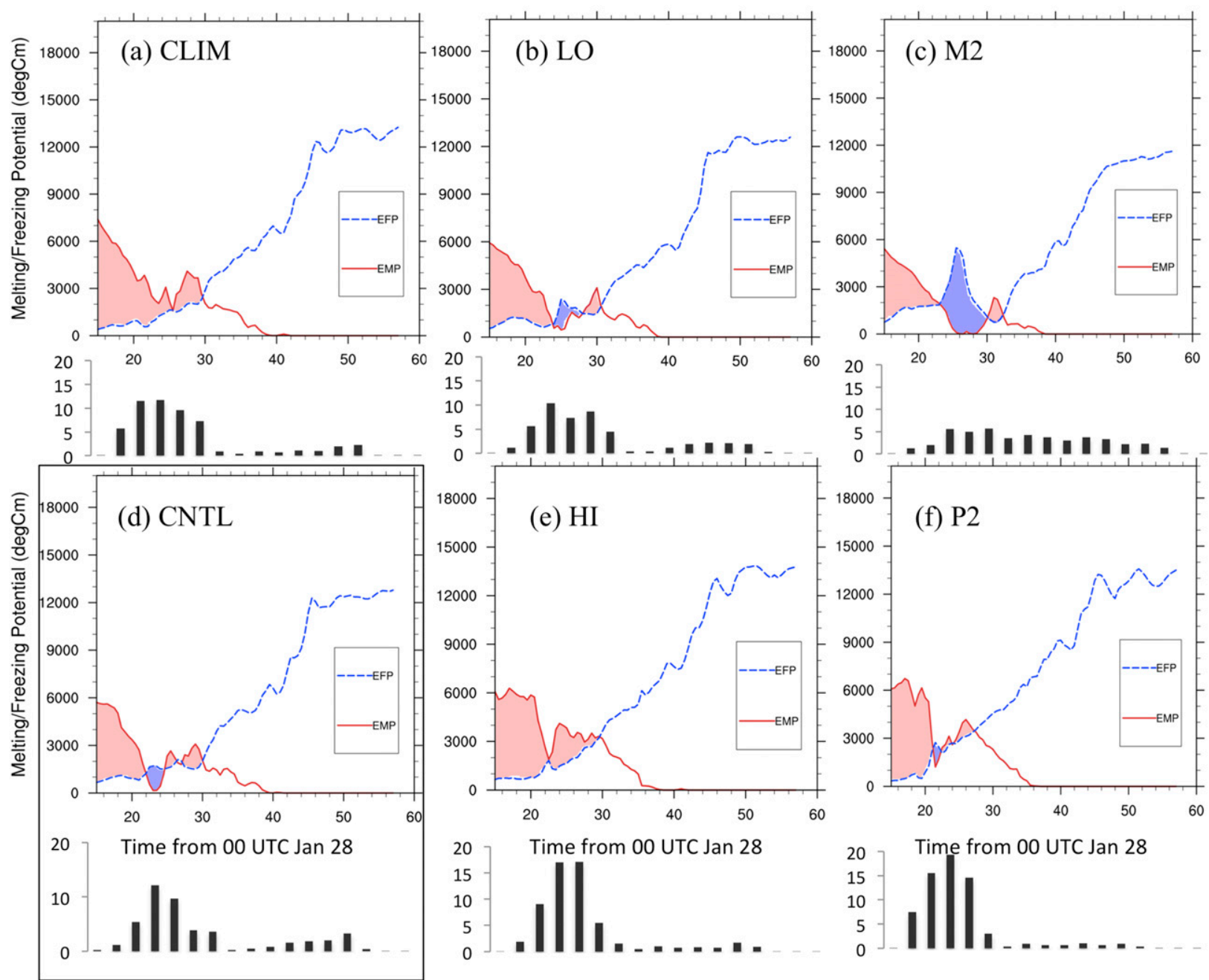

FIG. 8. Time series of EFP and EMP $\left({ }^{\circ} \mathrm{C} \mathrm{m}\right)$ for each SST simulation, derived from Eq. (2), between 1200 UTC 28 Jan $(t=12)$ and 1200 UTC $30 \operatorname{Jan}(t=60) 2010$ from D3. Values are a gridpoint average over the domain $34.9^{\circ}-35.3^{\circ} \mathrm{N}, 97.4^{\circ}-98^{\circ} \mathrm{W}$. Areas for which EMP is greater than EFP are shaded in red, and areas for which EMP is less than EFP are shaded in blue. Precipitation time series ( 3 hourly; mm) are averaged over the same sublocation and are displayed as a bar plot below each panel. CNTL is highlighted by a black box.

initially an EMP value of $\sim 6000^{\circ} \mathrm{C} \mathrm{m}$, decreasing rapidly after $t=20$ during heavy precipitation $\left(>5 \mathrm{~mm} \mathrm{~h}^{-1}\right)$.

The simulated profile evolution for western Arkansas (Fig. 9) indicated a thermal environment that is suitable for ice after $t=20$ (2000 UTC 28 January), with precipitation in the model after 0000 UTC 29 January $(t=$ 24). Warmer SST, particularly HI (Fig. 9e) and P2 (Fig. 9f), produced an earlier onset of heavy precipitation. After $t=24$, M2 never developed much of a warm layer (EMP $<500^{\circ} \mathrm{C} \mathrm{m}$ ), implying primarily ice pellets and snowfall, evident from the lack of ice accumulations in Fig. 5c. For LO (Fig. 9b) and CNTL (Fig. 9d), a temporary absence of the inversion was noted between $t=24$ and $t=28$ and then a redevelopment near $t=28$ (0400 UTC 29 January) was seen. This sequence potentially reflects cooling in the wake of a line of heavy (convective) precipitation to the south, which induced perturbations to the low-level wind field and an interruption in sustained warm-air advection (not shown). Warmer SST evolutions (CLIM, HI, and P2) show a deeper and persistent warm layer during precipitation. Relative to the depth of the refreezing layer, this warm layer was most pronounced for $\mathrm{P} 2$ and HI (EMP of $3000^{\circ}-6000^{\circ} \mathrm{C} \mathrm{m}$ ). These thermal differences help to explain the larger meridional changes in ice observed over Arkansas among the simulations.

\section{c. Dynamics}

SST was implicated in perturbing moisture content and low-level thermal properties, but changes to the winter-storm dynamics (height and pressure fields and 


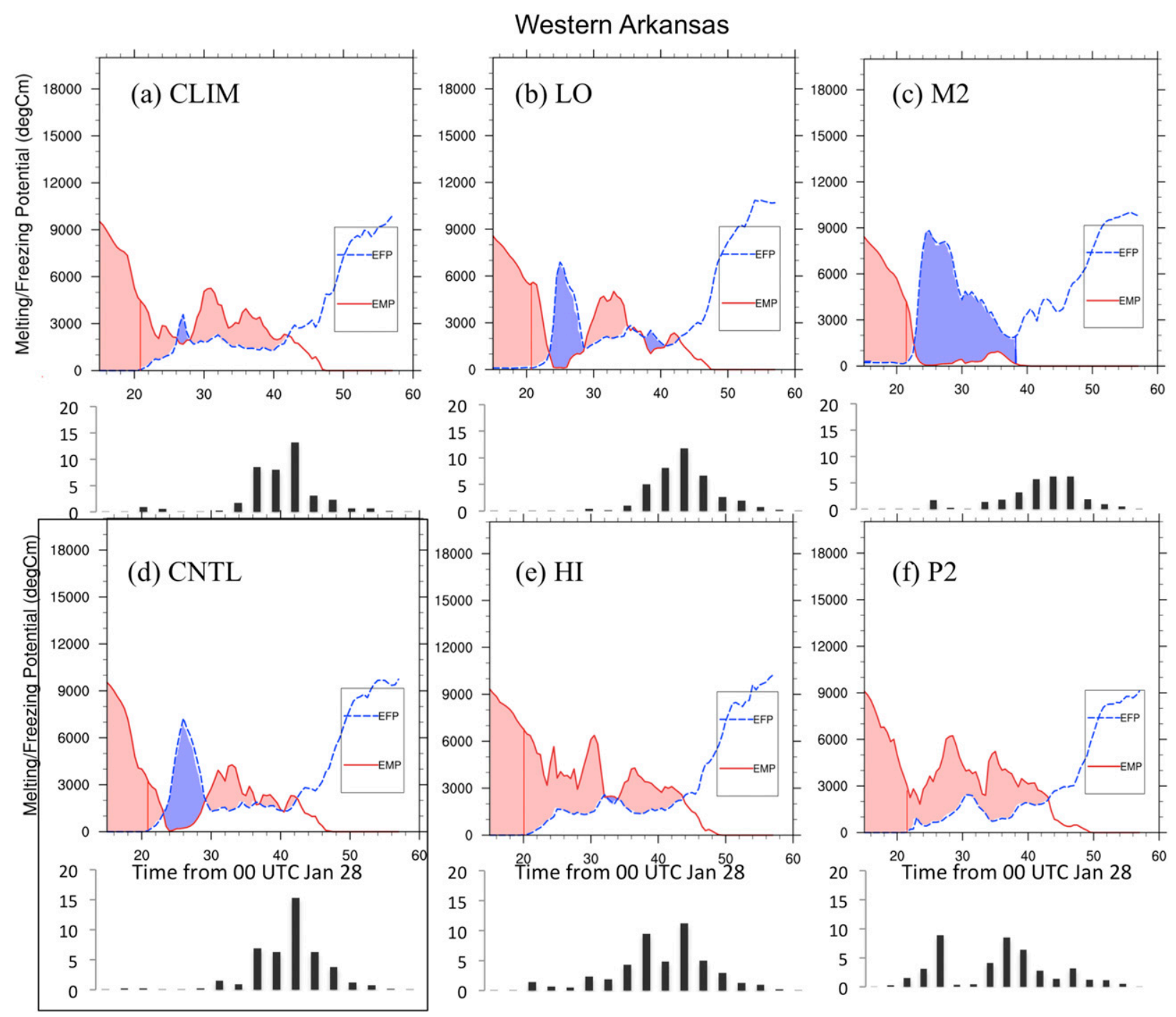

FIG. 9. As in Fig. 8, but for a subdomain of western AR $\left(34.7^{\circ}-35^{\circ} \mathrm{N}, 93.2^{\circ}-93.7^{\circ} \mathrm{W}\right)$. The red vertical line within each panel shows the approximate time at which EFP becomes greater than 0, after which freezing or frozen precipitation is possible.

winds) promoted by the altered low-level thermodynamic environment may feed back to enhance or mitigate precipitation response. A full account of the mesoscale dynamical evolution of this event is outside the scope of this paper, but, on the larger scale, precipitation formation was tied to strong ascent in a region of warm, moist air advection northeast of a weak 850 -hPa low. A cursory examination of the SST effects on warm-air advection and circulation strength was constructed using D2 midlevel thickness and SLP departures from CNTL respectively, shown in Fig. 10, and was displayed as a time mean during the main precipitation event over the central SGP domain (Oklahoma). The full dynamical impact of SST may be reduced as a result of analysis nudging of D1 in the mid- to upper troposphere.
Comparison of warmer SST (HI and P2; Figs. 10e,f) with cooler SST (LO and M2; Figs. 10b,c) indicates an increase in thickness tendencies, with a maximum difference on the order $\sim 4-5 \mathrm{~m}$ (per $2 \mathrm{~h}$ ) for the former, extending both north and eastward. Also of note was the decrease in SLP $(\sim 2-3 \mathrm{hPa})$ versus CNTL, extending from Texas into Oklahoma, southwest of the maximum thickness-tendency difference. To the west, more pronounced midlevel height falls and weak SLP rises were observed as SST increased. Comparison between CNTL, $\mathrm{M} 2$, and P2 for convection, low-level temperature, and wind fields (not shown) indicated strong condensational heating $\left(>4 \mathrm{~K} \mathrm{~h}^{-1}\right)$ for the latter over Oklahoma, implying a contribution of latent heat release to the thickness tendency. The 850-hPa geopotential circulation 

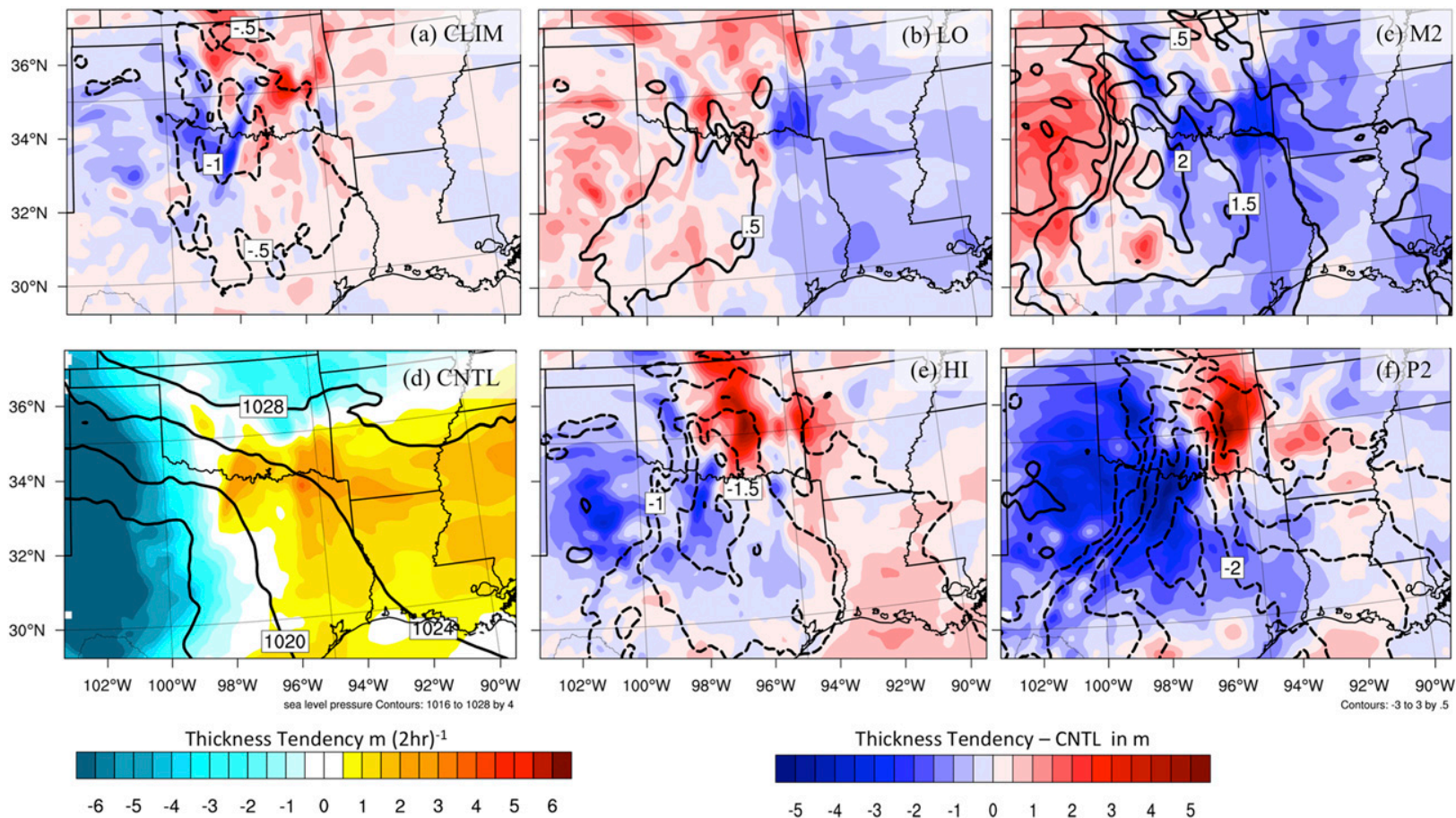

Thickness Tendency - CNTL in m

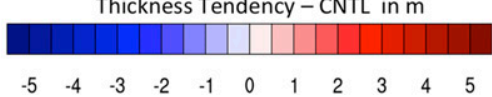

FIG. 10. For ARW D2, the 850-500-hPa 2-h thickness tendencies averaged over 1000 UTC 28 Jan-0000 UTC 29 Jan (shaded; m), with the $850-500-\mathrm{hPa}$ layer used in place of the 1000-500-hPa layer because of higher terrain in the west. (d) CNTL; (a)-(c), (e), (f) differences from CNTL. Time-averaged SLP (full, for CNTL) or differences from CNTL (hPa) are overlaid at intervals of $0.5 \mathrm{hPa}$ (dashed when $<0$ ).

also produced a deepening of $10-12 \mathrm{~m}$ and a northeastward shift of the minimum. The lower central height and increased geopotential height gradient across the SGP produced an enhanced southerly low-level jet on its eastern flank, on average $+7.5-10 \mathrm{kt}$ between $\mathrm{M} 2$ and $\mathrm{P} 2$ (not shown). This strengthened southerly flow is suspected to have supplied additional warm, moist air to the region. Figure 11 displays moisture transport during 28 January, calculated from Eq. (3) below, as based on the form used by Ressler et al. (2012):

$$
\tilde{Q}=\frac{1}{g} \int_{900 \mathrm{hPa}}^{400 \mathrm{hPa}} q \tilde{v} d p
$$

where $g$ is the acceleration of gravity $\left(9.81 \mathrm{~m} \mathrm{~s}^{-2}\right), q$ is mixing ratio $\left(\mathrm{g} \mathrm{kg}^{-1}\right)$, and $v$ is the horizontal $\mathbf{u}$ and $\mathbf{v}$ vector winds. A scalar magnitude was calculated from the wind field $\left(\times 10^{2} \mathrm{~kg} \mathrm{~m}^{-1} \mathrm{~s}^{-1}\right)$. The 900-400-hPa layer was used to capture changes in moisture associated with the southerly low-level jet. Warmer basin SST, regardless of anomaly distribution, produced a distinct increase in moisture transport, including a near doubling of the spatial area $>3.5 \times 10^{2} \mathrm{~kg} \mathrm{~m}^{-1} \mathrm{~s}^{-1}$ between $\mathrm{M} 2$ and $\mathrm{P} 2$, and an increase in maximum magnitude of nearly $50 \%$. For the physically constrained LO and HI, this difference was reduced $(\sim 150 \%$ increase in area and $100 \mathrm{~kg} \mathrm{~m}^{-1} \mathrm{~s}^{-1}$ maximum increase). The location of the maximum was also displaced eastward, reflecting faster eastward progression of attendant precipitation (e.g., Figs. 8 and 9). Heavy precipitation was focused along and north of the zone of maximum transport. By alternately fixing winds and mixing ratio at CNTL values and recalculating $\mathrm{M} 2$ and $\mathrm{P} 2$ moisture transport (not shown), the change in low-level winds appeared to control the observed trends at this time and location, but with a nonnegligible contribution from evaporation, particularly over northern Texas.

The observed changes in system movement have a strong impact on the timing of winter precipitation and its resultant intensity in any one region. Graff and LaCasce (2014) note that stronger systems tend to selfadvect more rapidly. SST-induced changes to the lowlevel baroclinic environment, resulting from modification of the regional meridional temperature gradient and static stability, were investigated by ascertaining the zonally and temporally averaged (1000 UTC 28 January -0000 UTC 29 January) Eady growth parameter [e.g., Lindzen and Farrell 1980; Graff and LaCasce 2014, their Eq. (1)] in Fig. 12. Potential temperature $\theta$ and differences in the vertical gradient of $\theta$ in eta coordinates were 

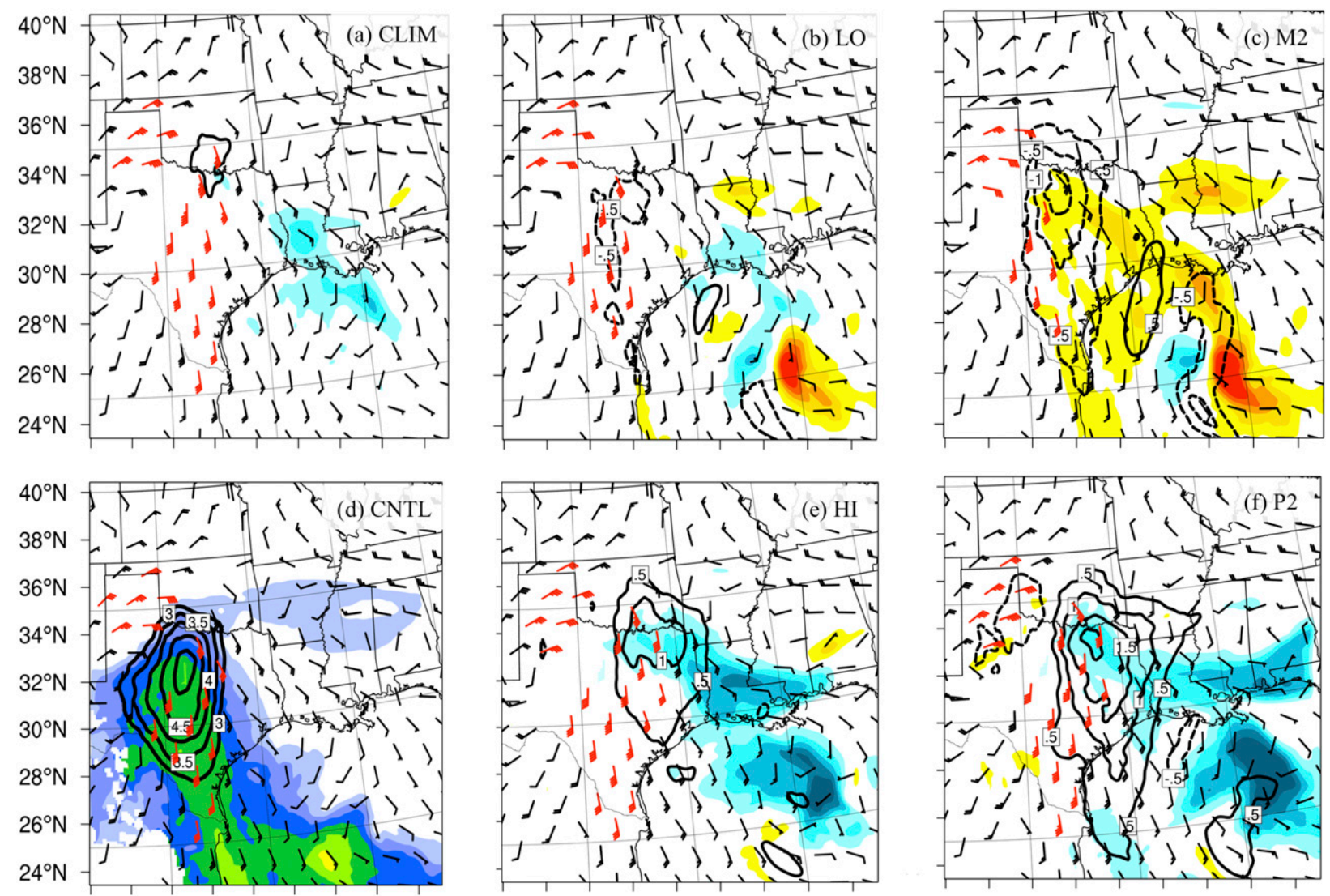

$104^{\circ} \mathrm{W} \quad 100^{\circ} \mathrm{W} \quad 96^{\circ} \mathrm{W} \quad 92^{\circ} \mathrm{W} \quad 88^{\circ} \mathrm{W} \quad 104^{\circ} \mathrm{W} \quad 100^{\circ} \mathrm{W} \quad 96^{\circ} \mathrm{W} \quad 92^{\circ} \mathrm{W} \quad 88^{\circ} \mathrm{W}$
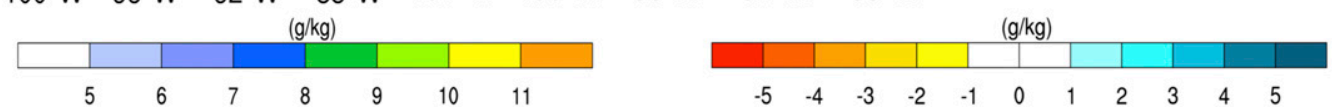

FIG. 11. For ARW D2, the 1200 UTC 28 Jan-0000 UTC 29 Jan averaged 850-hPa mixing ratio ( $\mathrm{g} \mathrm{kg}^{-1}$; shaded) and 900-400-hPa integrated horizontal moisture transport $\left(10^{2} \mathrm{~kg} \mathrm{~m}^{-1} \mathrm{~s}^{-1}\right.$; black contours) for (d) CNTL and (a)-(c),(e),(f) differences from CNTL (dashed contours $<0$ ). CNTL moisture-transport contours below $3 \times 10^{2} \mathrm{~kg} \mathrm{~m}^{-1} \mathrm{~s}^{-1}$ are not shown. Full wind fields at $850 \mathrm{hPa}$ are overlaid (barbs; $\mathrm{kt}$ ), with values $>30 \mathrm{kt}$ in red.

overlaid to infer perturbations in static stability. The magnitude of the variation in these parameters appeared to be proportional to the magnitude of the SST change. For HI (Fig. 12e), and especially P2 (Fig. 12f), lowertropospheric growth rates near $34^{\circ} \mathrm{N}$ (the latitude of strong low-level temperature gradient and $850-\mathrm{hPa}$ low) increased by up to $1 \mathrm{day}^{-1}(\sim 33 \%-50 \%)$. Additional heat increased the near-surface static stability in the vicinity of the surface front/maximum temperature gradient and decreased it aloft and to the south over the basin, with the reverse being generally true for M2 (Fig. 12c). A positive low-level potential vorticity (PV) anomaly was produced in the vicinity of the anomalous baroclinicity (shown in the figure in the online supplemental material). This PV anomaly was located in the vicinity of heavy precipitation and was enhanced for warmer SST, where simulations produced more widespread convection, suggesting a contribution from diabatic (latent) heating.

\section{d. Modification of air-parcel trajectories}

Following prior trajectory work by Gyakum and Roebber (2001) and Fuhrmann and Konrad (2013), we briefly consider the role of SST on airmass modification from ensemble air-parcel back trajectories terminating in the freezingprecipitation zone of southwestern Oklahoma (2100 UTC 28 January) during a peak in precipitation rates preceding the transition to ice pellets. Air-parcel histories terminating in the warm layer $(850$ and $725 \mathrm{hPa})$, near the surface $(975 \mathrm{hPa})$, and at midlevels $(500 \mathrm{hPa})$ were evaluated from 4-day (96h) back trajectories calculated using the ARW postprocessing software "RIP4" (https://www.mmm.ucar.edu/mm5/documents/ ripug_V4.html) for D1. Note that analysis nudging 

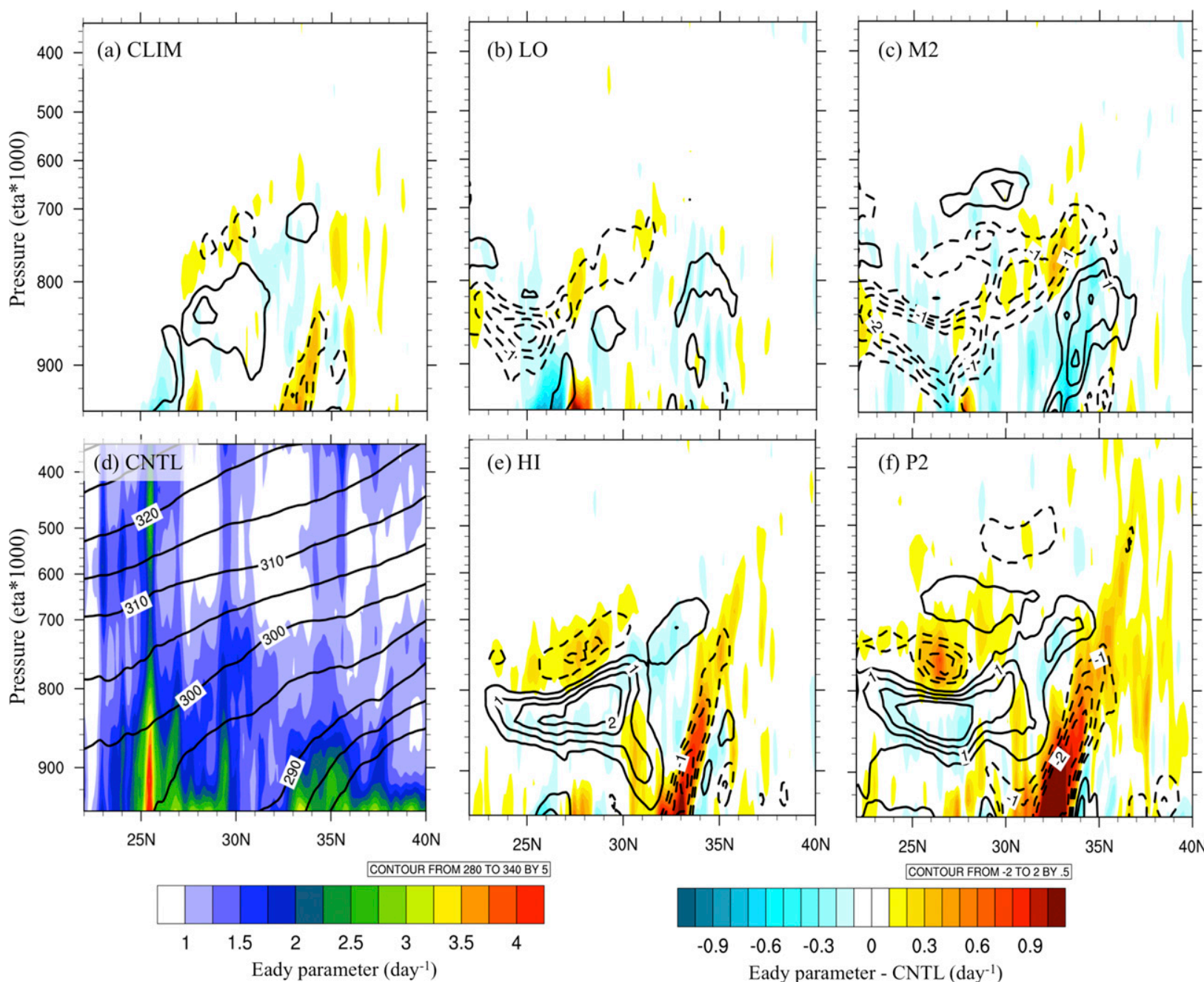

(e) HI

(f) P2
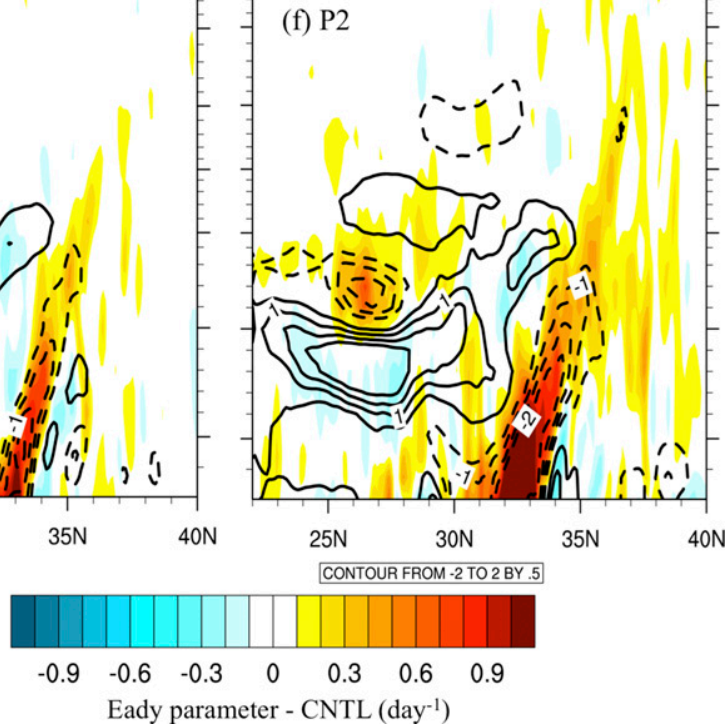

FIG. 12. Latitude-height Eady parameter $\left(\right.$ day $^{-1}$ ) between eta levels 10 and 34 (roughly 950-300 hPa) calculated using Eq. (1) of Graff and LaCasce (2014), averaged over the longitudinal extent of D2 and over time (1000 28 Jan-0000 UTC 29 Jan). (d) Full value for CNTL; (a)-(c),(e),(f) difference plots for the remaining SST perturbations. Also shown is change in potential temperature with a pressure proxy using eta $\times 1000\left[\mathrm{~K}(100 \mathrm{hPa})^{-1}\right]$. Positive (negative) values indicate increased (decreased) vertical spacing of potential temperature and reduced (increased) static stability.

of the mid-upper troposphere in this domain restricts complete freedom of variation in the trajectory path between simulations.

Since trajectory calculations are liable to uncertainties, including model resolution, wind field error, and integration errors (Fuhrmann 2011), an ensemble approach can better account for the range of potential paths resulting from small horizontal and vertical displacements. Here, 100 back trajectories were initiated from a $3 \times 4$ grid domain (approximately 1 trajectory per $3.6 \mathrm{~km}$ ), which is shown for each level in Fig. 13. Altitude perturbations were not considered. The calculations output the location every $30 \mathrm{~min}$, from 3-hourly input data, suggesting interpolation error was possible, particularly with higher wind velocities, as reflected in the greater divergence of paths with increased altitude (Figs. 13c,d). A simple method was applied to extract a "most common" path by first subdividing the region into $25 \times 30$ grid points that focus on areas of trajectory location at $t=96 \mathrm{~h}$ (i.e., the end of the calculation, where path divergence is presumably greatest; see the boxes in Figs. 13a-d). A single trajectory path from each of these regions was correlated against all remaining paths, with a threshold value of $>0.9$ for inclusion. Time and software limitations precluded a more sophisticated statistical analysis, but the identified paths in each group shown were found to be representative of the range of simulated trajectories. Only the grouping with the highest number of member paths was retained. In general, the dominant CNTL group was reflected across 

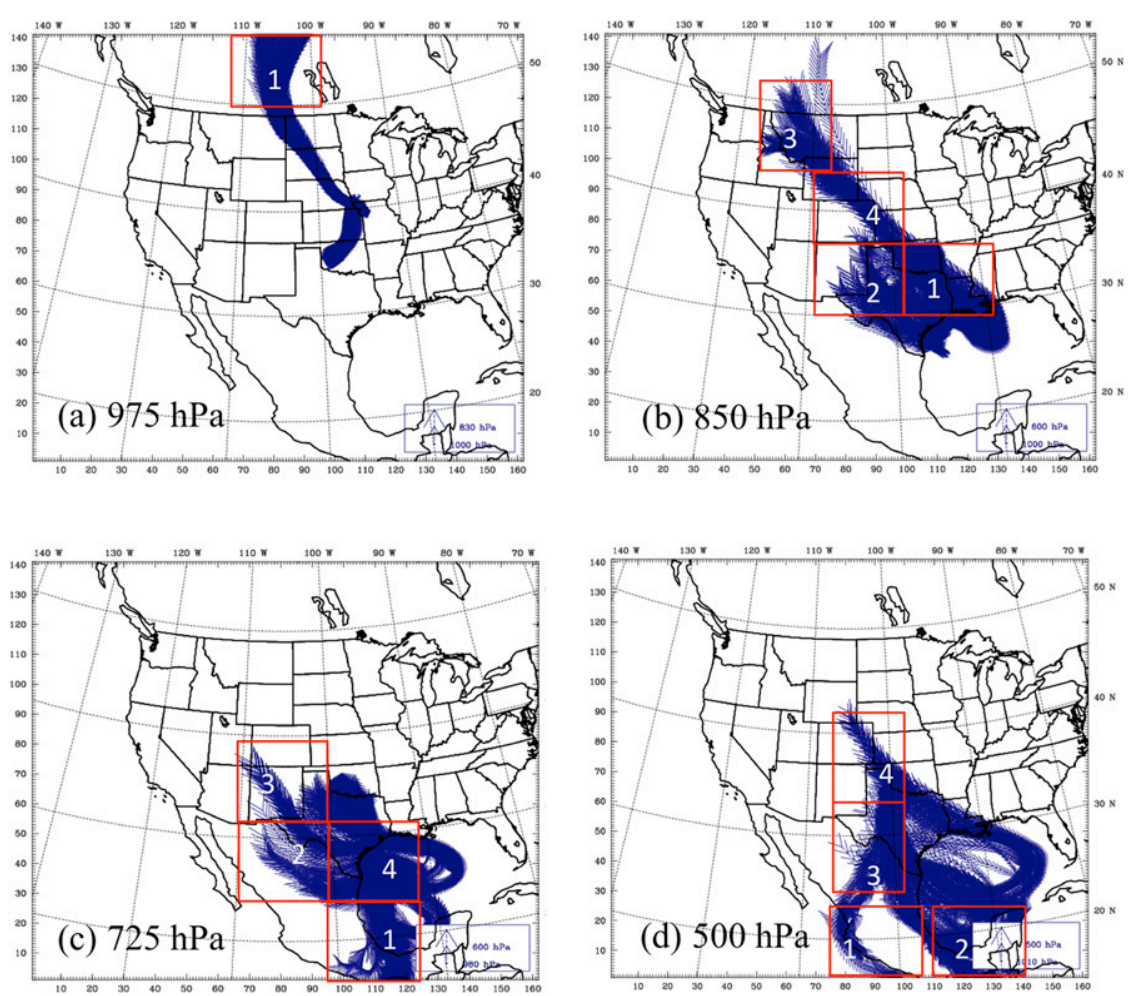

FIG. 13. Distribution of one hundred 96-h back trajectories (blue contours) initiated from the CNTL simulation over a $3 \times 4$ gridpoint domain over southwestern and western Oklahoma, terminating at (a) 975, (b) 850 , (c) 725 , and (d) $500 \mathrm{hPa}$ at 2100 UTC 28 Jan. Subdomains corresponding to frequently observed trajectory locations at $t=96$ are defined by a set of $25 \times$ 30 gridpoint grids (red boxes), which is used to initially classify common trajectory paths and aid in the subsequent grouping of individual members.

simulations. There were changes in the proportions for each, suggesting some effect of SST on circulation. For the 850- and 725-hPa layers, four initial groups were reduced to two on the basis of the plotted similarities and overlap of identical ensemble members. The resulting mean paths are shown in Fig. 14, with antecedent 48-h GOM SST (shaded) and latent heat flux (contours) overlaid. Altitudes are shown in Fig. 15 for each simulation and level, along with simulated PBL heights following the air parcels (Figs. 15b-d). The latter were used to determine the approximate duration of the period in which the air parcel resides within the marine PBL, which affects the magnitude of heat, moisture, and momentum exchange.

At the 975-hPa level (Figs. 14 a-f; blue lines with triangles), trajectories reflected the movement of air parcels in the Arctic continental air mass, which was largely uninfluenced by SST. The southwestward path implied cold-air advection. The close spacing of 6-hourly location markers suggested weak winds at this time. Farther aloft at $850 \mathrm{hPa}$ (Figs. 14a-e; black lines with circles), the common mean path moved southward from the continent, in conjunction with earlier cold-air penetration (e.g., Fig. 2b), and curved anticyclonically over the far northern GOM, before ascent into the freezing-precipitation zone (Fig. 15b). The PBL depth in the vicinity of the northern basin varied among simulations and trajectory paths (Figs. 14 and 15b). For air parcels that moved into the basin, a deeper PBL was evident, with the exception of in $\mathrm{P} 2$, the air parcels of which remained largely onshore. The mean path was displaced northward for HI and P2, relative to CNTL. From prior evidence for low-level circulation changes and a more progressive system for P2 (Figs. 10 and 11), the trajectory implied backed low-level winds, limiting advection from the ocean.

Thermal and moisture profiles following the air parcel incident to $850 \mathrm{hPa}$ are shown in Fig. 16. Heat and moisture were accumulated primarily as the air parcel descended into the marine PBL (Fig. 15b). The PBL structure over the basin appeared to respond to SST, with increased depth over zones of warmer water. Run M2, for example, indicated a shallow, stable marine PBL offshore over the cool coastal shelf waters (from $t=54$ 

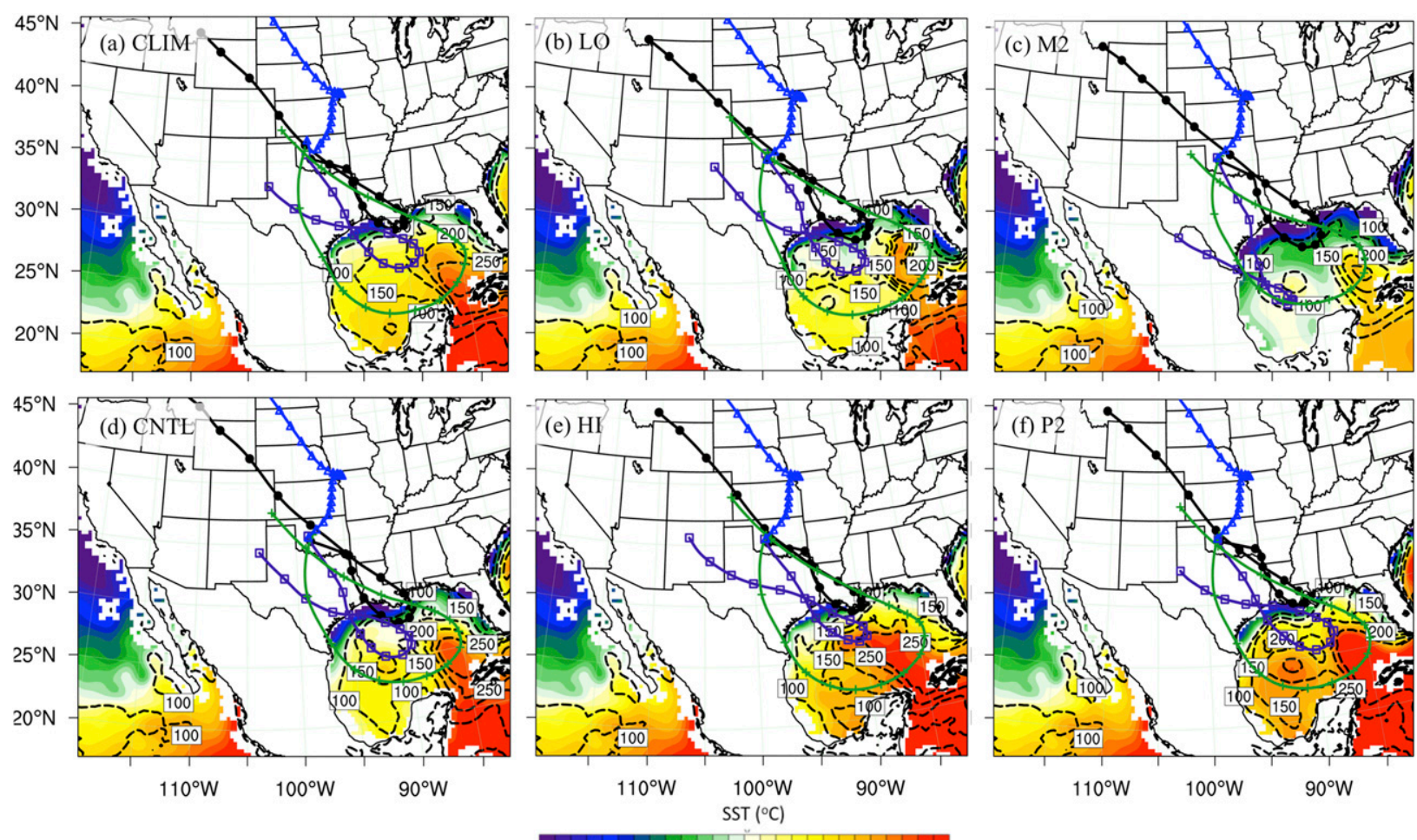

$\begin{array}{lllllllllllll}15 & 16 & 17 & 18 & 19 & 20 & 21 & 22 & 23 & 24 & 25 & 26 & 27\end{array}$

FIG. 14. The 96-h mean air-parcel back trajectories for each perturbed-SST simulation (D1), as based on the derived most common paths from analysis of 100 back trajectories terminating over southwestern/western Oklahoma at 2100 UTC 28 Jan. Blue with triangular markers $=975 \mathrm{hPa}$, black with circular markers $=850 \mathrm{hPa}$, purple with square markers $=725 \mathrm{hPa}$, and green with cross markers $=500 \mathrm{hPa}$. Markers are separated by 6 -h intervals. SST (shaded; ${ }^{\circ} \mathrm{C}$ ) and upward latent heat flux $\left(\mathrm{W} \mathrm{m}^{-2}\right.$, contoured over ocean for $>50 \mathrm{~W} \mathrm{~m}{ }^{-2}$ ) are also displayed as a 48-h average ending at 2100 UTC 28 Jan.

to $t=42$ ). Conversely, reduced SST gradients over this shelf region in HI may have enhanced PBL depth and the magnitude of temperature and moisture increases, despite limited parcel duration offshore (Figs. 14e, 15b, and 16). P2 largely resided onshore and above the PBL, resulting in a more limited rate of heat and moisture increase during its recurvature and, ultimately, a cooler air mass, which was consistent with the sharp decrease in warm-layer EMP at trajectory termination (Fig. 8f). The combination of SST, PBL depth, trajectory location, and trajectory altitude controls the specific evolutions of temperature and moisture in Fig. 16, which are themselves influenced by the larger-scale circulation changes.

Larger effects of SST are shown at the 725- (Figs. 14a-f; purple lines with squares) and 500-hPa (Figs. 14a-f; green lines with crosses) levels, resulting from their broader more southerly path over the basin, and at lower altitude, possibly resulting from increased subsidence, placing air parcels under the influence of a deeper marine PBL (Figs. 15c,d). For the former, diabatic fluxes of heat and moisture increased once air parcels descended into the marine $\mathrm{PBL}$ (near $t=50$ ). The M2 trajectory, traversing a different region of the GOM, never descended into the PBL, moving over a cooler SST zone, resulting in weak and generally adiabatic changes in its thermal properties (Figs. 15c and 17a-c). For HI, the initially higher altitude delays the air-parcel descent, such that more rapid increases occurred after $t=40$. At this time, the air parcel was aloft of anomalously warm SST and $250 \mathrm{~W} \mathrm{~m}^{-2}$ latent heat flux (Fig. 14e). These warm northern-basin SST favorably aligned with the trajectory for the subsequent $24 \mathrm{~h}$, yielding an increase in mixing ratio $\left(\sim 6 \mathrm{~g} \mathrm{~kg}^{-1}\right)$, air temperature $\left(2.5^{\circ} \mathrm{C}\right)$, and equivalent potential temperature $\theta_{e}(22 \mathrm{~K})$. The P2 and CLIM runs (Figs. 14f, 14a, and 17) showed similar evolutions but of lesser peak magnitude than HI. Both trajectories moved over a prominent warm area northeast of the Yucatan Channel from $t=54$ to $t=48$ and subsequently into a region of cooler SST and weaker latent heat flux $\left(\sim 150 \mathrm{~W} \mathrm{~m}^{-2}\right)$ after $t=36$, particularly for CLIM (Fig. 17b). By the time the air parcels moved onshore, at approximately $t=18$, air temperature (Fig. 17b) and mixing ratios (Fig. 17c) for $\mathrm{HI}$ were $0.2^{\circ} \mathrm{C}$ and $1 \mathrm{~g} \mathrm{~kg}^{-1}$ higher than those for $\mathrm{P} 2,1.5^{\circ} \mathrm{C}$ and $1 \mathrm{~g} \mathrm{~kg}^{-1}$ higher than those for CLIM, $2.5^{\circ} \mathrm{C}$ and $2 \mathrm{~g} \mathrm{~kg}^{-1}$ higher 

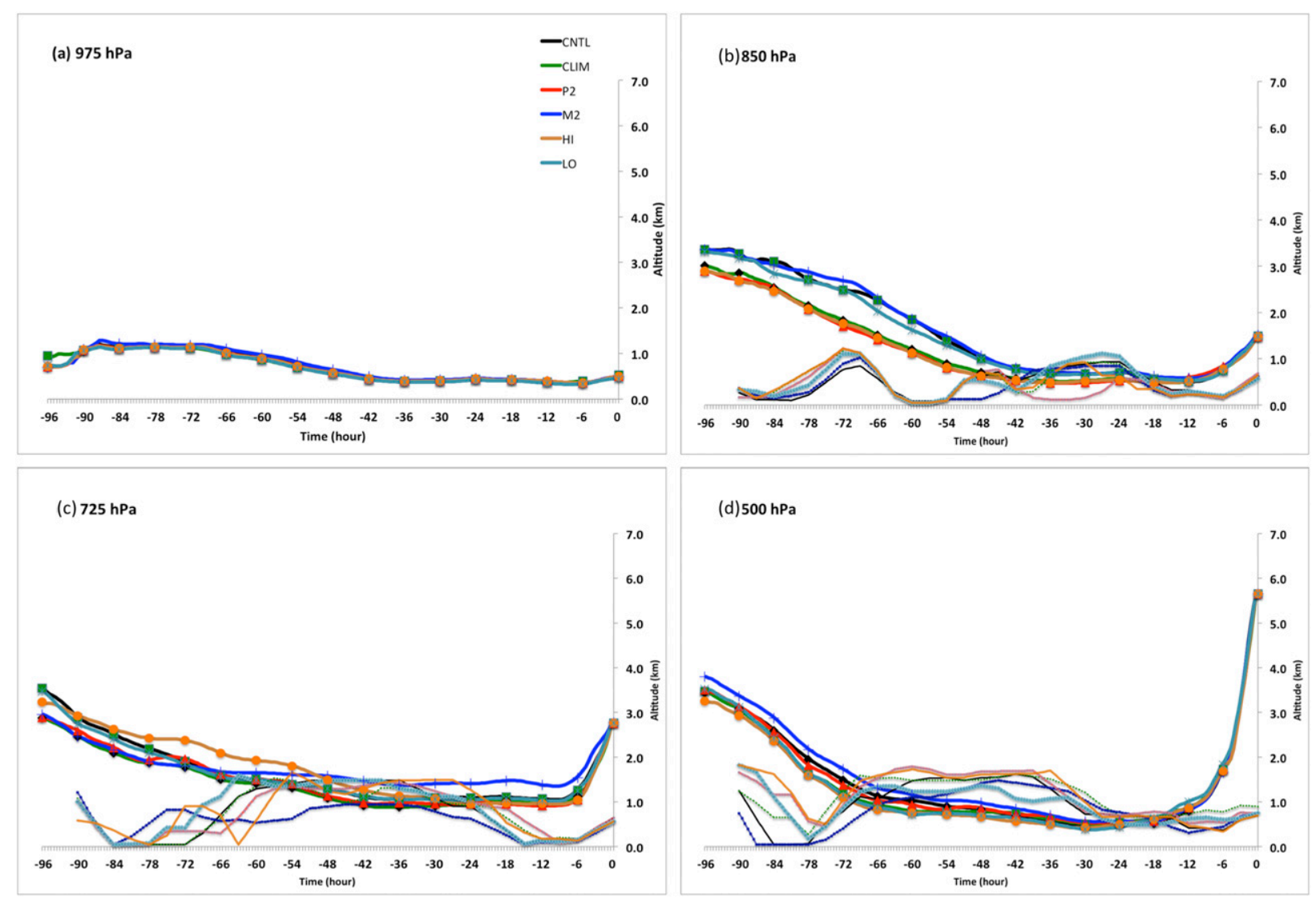

FIG. 15. Air-parcel back-trajectory altitudes (lines with markers) and PBL heights (lines without markers) for each atmospheric layer in Fig. 14. The legend shows the corresponding line color (both line types) for each SST simulation.

than those for CNTL, and $5.5^{\circ} \mathrm{C}$ and $4 \mathrm{~g} \mathrm{~kg}^{-1}$ above those for M2. For the 725-hPa layer, reflecting the upper warm nose, the anomalous warmth in the northern GOM appeared to be a factor in retaining greater warmth onshore, in particular for $\mathrm{HI}$, but precipitation anomalies were greatest for P2 (Figs. 16d, 17d, and 18d).

Synoptic ascent typically maximizes in the midtroposphere, which is evident for the 500-hPa layer in Fig. 15d. The airmass properties into this layer therefore strongly influence the precipitation intensity response. Figure 15d indicates that trajectories for each simulation were within the marine PBL for at least $40 \mathrm{~h}$, and, with little variation in trajectory path/altitude, the SST field probably drove the thermodynamic response. The meteorological characteristics (Fig. 18) showed persistent diabatic modification over this time, resulting in high total mixing ratios and $\theta_{e}$ lifted into the precipitation zone. The subbasin SST distribution and latent heat modified the timing and peak rates of moisture and heat flux into the trajectory parcels (Fig. 14), but the warmer basinwide SST in CLIM, HI, and P2 enabled additional heat to be supplied and retained (Figs. 18a-c). Just prior to ascent, the maximum differences in $\theta_{e}$ were $+4(\mathrm{P} 2)$ and $-6(\mathrm{M} 2) \mathrm{K}$ and in mixing ratio were $+1(\mathrm{P} 2)$ and -1.5 (M2) $\mathrm{g} \mathrm{kg}^{-1}$ relative to CNTL.

\section{Discussion}

This study examined the thermodynamic response of an SGP winter storm to a range of idealized GOM SST perturbations. Of particular interest was the reevaluation of conclusions by Ramos da Silva et al. (2006) that warmer SST lead to an intensified warm layer and an increase in freezing precipitation. This result was generally consistent, with some notable departures in precipitation intensity from CNTL even for modest SSTA (e.g., CLIM). Nonlinearity in the simulated precipitation response was observed, associated with the interaction of thermal, dynamic, and baroclinic processes.

The nonmonotonic increase in icing severity with basin-average SST was reflected in Fig. 5. Although ice accumulation is not necessarily a 1:1 ratio with total liquid precipitation equivalent (because of multiple 
2100 UTC Jan $28850 \mathrm{hPa}$

(a)

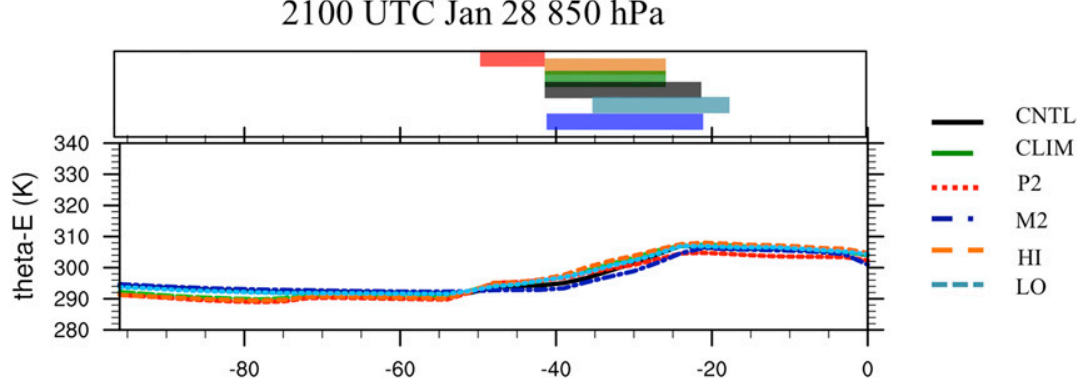

(b)

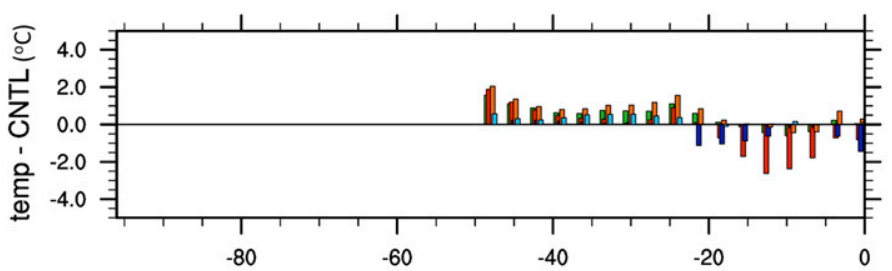

(c)

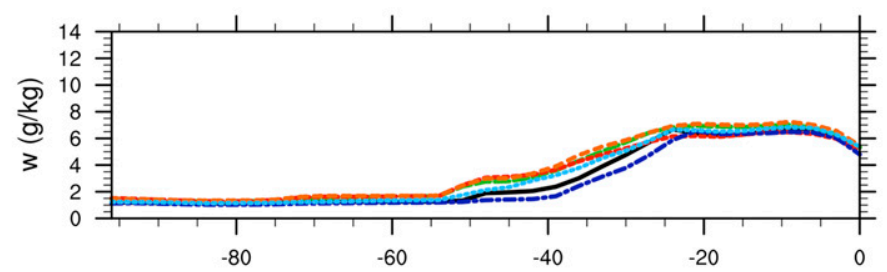

(d)

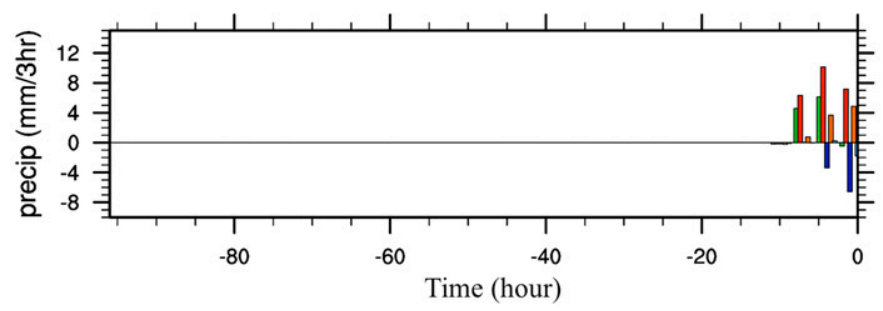

FIG. 16. Select temperature and moisture variables along 850-hPa air-parcel back trajectories (see also Figs. 14 and 15): (a) equivalent potential temperature (K); (b) air temperature difference from CNTL (bar plot; ${ }^{\circ} \mathrm{C}$ ) for the period of diabatic heating/moistening corresponding to the descent of trajectories into the GOM/marine PBL, the duration of which is highlighted for each simulation by the color-coded horizontal bars. Temperature differences prior to this time were set to zero. (c) Mixing ratio $\left(\mathrm{g} \mathrm{kg}^{-1}\right)$ and (d) precipitation difference from CNTL as an average over the 850-, 725-, and 500-hPa layers between $t=15$ and $t=0$ (bar plot; mm).

factors, including air temperature, wind direction/speed, composition of impacted surface, and heat fluxes), it is reasonable to suspect that areas of highest precipitation equivalent should expect more icing. Cooler SST produced a greater percentage change for accumulated precipitation and precipitation rates in total, and for the ice region, relative to the proportional positive SST perturbations (Table 4). However, peak ice accumulations, particularly for Oklahoma, maximized in CLIM and $\mathrm{HI}$ and not in P2 (Fig. 5), supporting a more deleterious ice storm for southwestern Oklahoma (CLIM) and central Oklahoma (HI and P2). From this work, the prominent factor in ice accumulation and location changes was the altered system progression, itself contributing to spatial and temporal changes in the thermal profile, and moisture transport (Figs. 10 and 11). SST differences forced altered low-level temperature gradients and static stability (Fig. 12), suggesting a positive dynamic and kinematic feedback, where warmer SST enhanced the onshore, low-level baroclinicity to the south and aloft of the cold air. Richer low-level moisture and enhanced warm air and moisture advection into the eastern quadrant of the $850-\mathrm{hPa}$ cyclonic circulation promoted additional height/pressure falls at the surface and low levels. A deeper low translated eastward more rapidly, yielding earlier-forming, more extensive, and heavier precipitation that also propagated faster to the east (Figs. 5-9). The opposite was generally true for cooler SST. Trends in system progression were apparent, but of lower 
(a)

2100 UTC Jan $28725 \mathrm{hPa}$

(b)
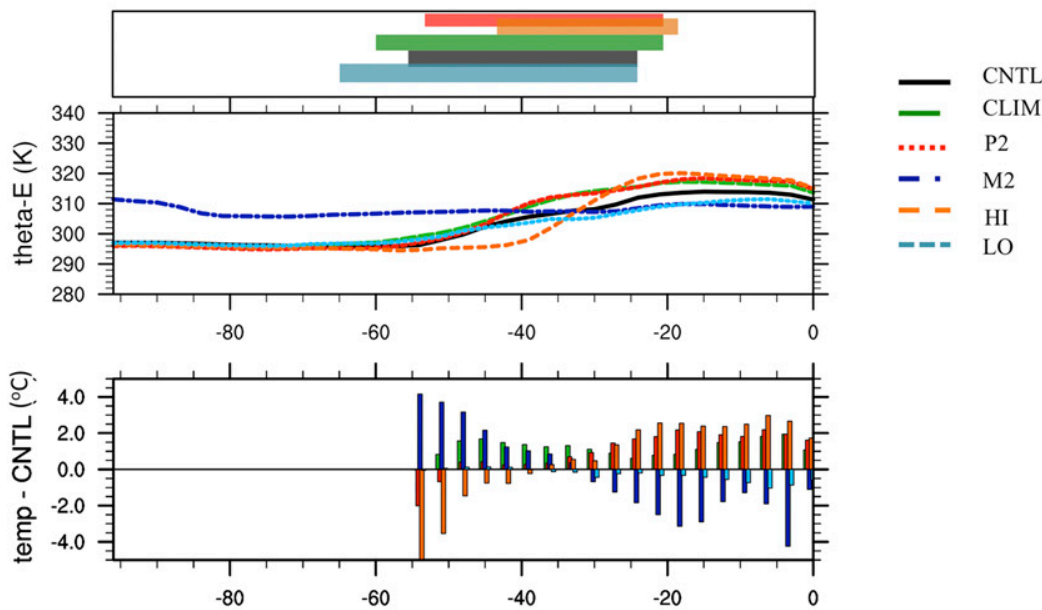

(c)

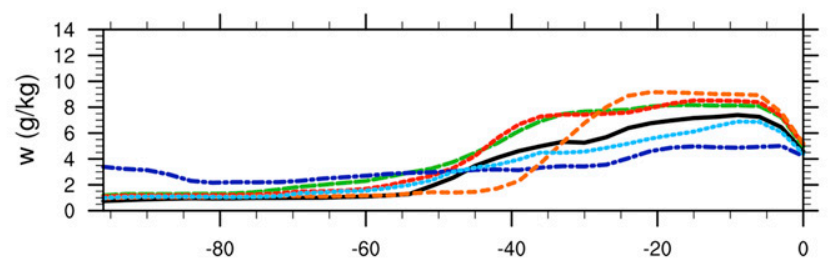

(d)

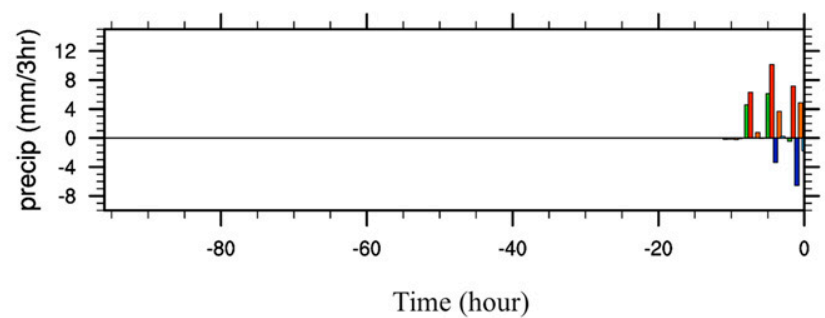

FIG. 17. As in Fig. 16, but for back trajectories terminating at $725 \mathrm{hPa}$.

magnitude, as basin-averaged departures decreased (CLIM, LO).

When examining all precipitation phases, and especially rainfall, total accumulations increased monotonically with increased basin SSTA. In the ice region, the faster progression was likely the principal reason for the lower maximum and broader spatial accumulations over Oklahoma in P2 (Fig. 5). Cooling of the warm layer occurred earlier over southwestern Oklahoma, potentially the product of both altered circulation and initially more intense precipitation (e.g., Figs. 8f and 16), whereas warm-layer intensity was enhanced over westcentral Arkansas (Fig. 9f). These factors raised the possibility that an increased proportion of more intense precipitation in $\mathrm{P} 2$ fell out of the algorithm classification for ice in southwestern Oklahoma. Despite CLIM and $\mathrm{HI}$ also exhibiting increased precipitation (promoting melting-induced cooling), lower-magnitude changes in system dynamics supported increased duration of the warm-layer inversion. Trajectory analysis implicated the warm northern GOM in $\mathrm{HI}$ in supplying additional warmth to this layer (Figs. 14-18). Parsing out the impact of the varying SST structures used, including SST gradients, requires further investigation, but preliminary results from an additional simulation, in which the basin-average anomaly of HI was applied uniformly to the climatological field, suggested that the role of specific anomaly structures may not be as important to potential icing severity as the sign and magnitude of the broader anomaly field (not shown). The M2 simulation showed the greatest opposing thermodynamic change, with a weaker and more southerly $850-\mathrm{hPa}$ low, reduced northward penetration of moisture and warmth (resulting in southward displacement of the snow line), and lower precipitation rates spread out over longer duration (Figs. 5c, 6c, 7c, 8c, and 9c).

Air-parcel trajectories (Figs. 13-18) revealed examples of specific path, altitude, and source regions during 
2100 UTC Jan $28500 \mathrm{hPa}$

(a)

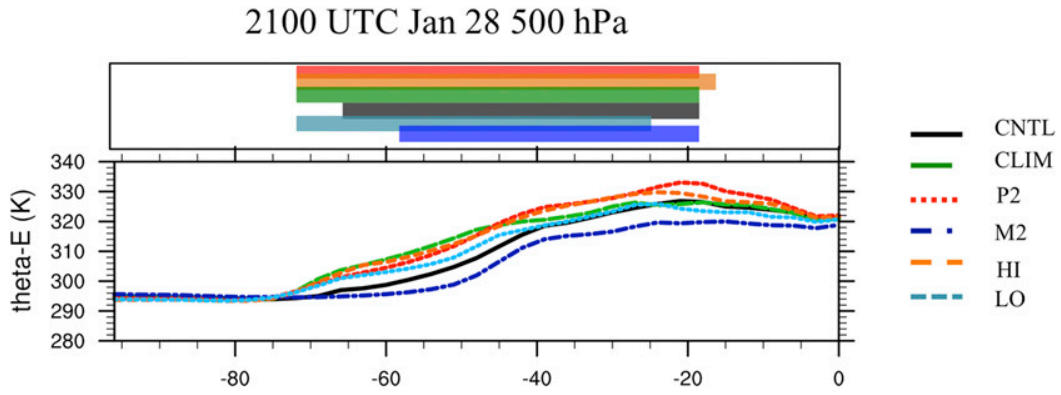

(b)

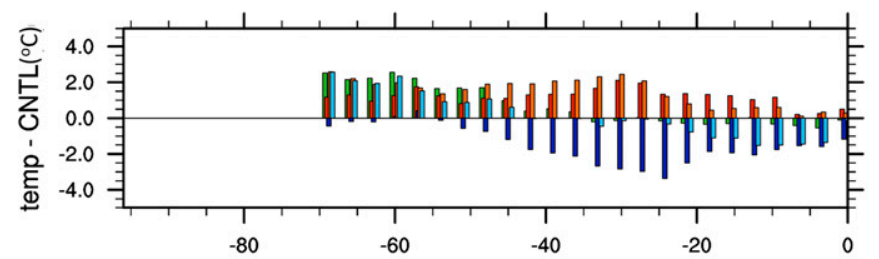

(c)

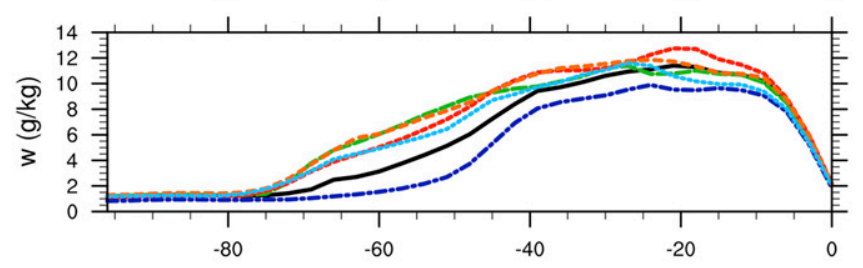

(d)

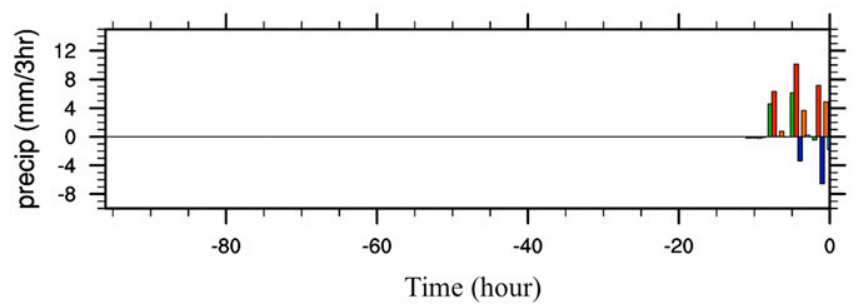

FIG. 18. As in Fig. 16, but for back trajectories terminating at $500 \mathrm{hPa}$.

the latter stage of heavy icing over southwestern Oklahoma. Descent, heating, and moistening of air parcels over the GOM was confirmed, physically linking location and magnitude of SST anomalies to heat and moisture accumulation. Variations in mean trajectory paths, altitudes, and PBL characteristics also exerted strong influence on airmass modification, in some cases mitigating the SST contribution (Figs. 15b and 16). Marine PBL depth varied with SST, particularly over the northern coastal shelf, in which increased SST promoted greater PBL depth and longer trajectory residence times within the PBL, accentuating the degree of diabatic fluxes into the air parcel. Furthermore, trajectories of the air parcels incident to the level of strong ascent (Figs. 14 and 18) showed that enhanced moisture gained from a warmer GOM drove intensified precipitation. Last, although the evolutions shown here depend on the meteorological characteristics of this individual case, an identical set of perturbations was applied to another event: a major ice storm during
9-11 December 2007. Many of the major findings were replicated (not shown). The December 2007 storm was a long-duration, convective freezing-rain episode with a pronounced warm layer $\left(>8^{\circ} \mathrm{C}\right)$ north of a quasistationary front. Cooler SST reduced the potential instability of the lower troposphere by decreasing the warm-layer magnitude near $850 \mathrm{hPa}$. The M2 precipitation reduction was markedly greater than the increase resulting from enhanced convective intensity with warmer SST. Time-evolving changes in this event mitigated differences from SST during the latter period of the storm, also implying a complex interplay of thermal and dynamic processes.

\section{Summary}

This paper has evaluated the thermal, dynamic, and precipitation response of the winter storm of 28-30 January 2010 to idealized Gulf of Mexico SST perturbations, in a high-resolution nested ARW sensitivity 
study. Five SST scenarios were simulated, including a 1981-2010 climatological mean, uniform $\pm 2^{\circ} \mathrm{C}$ from a control run, and a physically constrained upper and lower limit and distribution from a 30-yr dataset. Key results were summarized in the discussion. Each perturbation yielded a discernable response to precipitation accumulation, location, and intensity, including the area of freezing precipitation. These results have expanded upon those of Ramos da Silva et al. (2006) for a different subdomain of the United States and remain one of the few studies to examine oceanic influence on inland precipitation events at short time scales. The SST used were substantially greater as a basin average than those expected from observational error. For example, Kara and Barron (2007) examine the performance of the $0.5^{\circ}$ RTG_SST dataset against in situ buoy data for multiple locations within the tropical and coastal Atlantic Ocean and tropical Pacific Ocean, identifying RMSE of generally less than $0.4^{\circ} \mathrm{C}$. Differences between popular datasets used as input to NWP models may be locally greater, particularly in regions of strong gradients, such as the Gulf Stream and winter continental shelf (e.g., Chelton and Wentz 2005). It is therefore possible that SST uncertainty can affect simulations of inland systems, as demonstrated here, particularly at longer lead times, and if broad biases exist within the fetch of moisture and temperature advection.

Further physical insights could be gained from this event, including additional experiments to determine whether high-resolution input SST and SST-gradient structures discernably alter our results, which tests the assumption that large-scale SST features play a dominant role. The spatial distribution of imposed anomalies (e.g., uniform vs regional across the GOM basin) should also be further examined. This work investigated mixedphase precipitation associated with complex microphysical processes, and additional research is necessary to determine specific phase-type and thermal-profile sensitivities to the microphysics schemes used.

This study is applicable to forecasters evaluating moisture availability and quantitative precipitation estimation in advance of similar winter systems coincident with warm/cool SST (e.g., Case et al. 2011; Lebeaupin et al. 2006). It emphasizes the importance of including accurate and evolving input SST data in numericalmodel simulation of these events. Over seasonalinterannual time scales, SST evolutions can be influenced by solar radiation and cloud cover, wind forcing, atmospheric teleconnections, and synoptic-scale variability (e.g., frequency of cold-air intrusions into the basin). The frequency of SGP winter storm regimes during any given winter is similarly affected by the largescale circulation, and a physical link, if any, between anomalous SST regimes and freezing-precipitation frequency is presently unknown. Therefore, our results are primarily relevant to SST conditions immediately preceding winter weather and cannot be used to infer any broader trends. Nevertheless, the twenty-first century potentially is a transition period, with superposition of impacts from natural climate variability and increasing warming due to anthropogenic climate change (e.g., Trenberth 2012; Courmou and Rahmstorf 2012). Climate change is expected to lead to an increase in mean winter temperatures of varying amplitude throughout the contiguous United States. Future trends in cold-air outbreaks and winter storms remain uncertain (e.g., Deser et al. 2012; Vavrus et al. 2006), however, and are unlikely to disappear. Most ocean SST are increasing and/or experience known periodic variability, impacting atmospheric circulation and moisture availability (e.g., IPCC 2013; S.-P. Xie et al. 2010). This study may therefore contribute to the discussion of the intersection of cold-weather events in a warming world.

Acknowledgments. The authors acknowledge the contribution of Dr. Peter Lamb to this project. Sadly, Dr. Lamb passed away during the completion of this work. This work was part of E. Mullens's dissertation research and was supported by the Atmospheric System Research (ASR) program of the U.S. Department of Energy (Grant DE-FGDZ-05ER64062). Additional funding was from the NOAA-University of Oklahoma cooperative agreement NA080AR4320904. Project computing was performed at the University of Oklahoma Supercomputing Center for Education and Research (OSCER). NCEP NARR was provided by NOAA/OAR/ERSL PSD of Boulder, Colorado (http://www.ersl.noaa.gov/psd/). The Model Evaluation Tools were developed at NCAR through grants from the U.S. Air Force Weather Agency (AFWA) and NOAA. NCAR is sponsored by the National Science Foundation. We also thank two anonymous reviewers in particular for their helpful comments and suggestions, which have considerably improved this paper.

\section{REFERENCES}

Bernadet, L., J. Wolff, L. Nance, A. Loughe, B. Weatherford, E. Gilleland, and B. Brown, 2009: Comparison between ARW and NMM objective verification scores. Preprints, 23rd Conf. on Weather Analysis and Forecasting/19th Conf. on Numerical Weather Prediction, Omaha, NE, Amer. Meteor. Soc., 5A.2. [Available online at https://ams.confex.com/ams/pdfpapers/ 153552.pdf.]

Bernstein, B. C., 2000: Regional and local influences on freezing drizzle, freezing rain, and ice pellets. Wea. Forecasting, 15, 485-508, doi:10.1175/1520-0434(2000)015<0485: RALIOF $>2.0 . \mathrm{CO} ; 2$ 
Bond, N. A., M. F. Cronin, and M. Garvert, 2010: Atmospheric sensitivity to SST near the Kuroshio Extension during the extratropical transition of Typhoon Tokage. Mon. Wea. Rev., 138, 2644-2663, doi:10.1175/2010MWR3198.1.

Booth, J. F., L. Thompson, J. Patoux, and K. Kelly, 2012: Sensitivity of midlatitude storm intensification to perturbations in the sea surface temperature near the Gulf Stream. Mon. Wea. Rev., 140, 1241-1256, doi:10.1175/MWR-D-11-00195.1.

Bourgouin, P., 2000: A method to determine precipitation types. Wea. Forecasting, 15, 583-592, doi:10.1175/1520-0434(2000)015<0583: AMTDPT $>2.0 . \mathrm{CO} ; 2$.

Brock, F. V., K. C. Crawford, R. L. Elliot, G. W. Cuperus, S. J. Stadler, H. L. Johnson, and M. D. Eilts, 1995: The Oklahoma Mesonet: A technical overview. J. Atmos. Oceanic Technol., 12, 5-19, doi:10.1175/1520-0426(1995)012<0005:TOMATO > 2.0.CO;2.

Call, D. A., 2009: As assessment of National Weather Service warning procedures for ice storms. Wea. Forecasting, 24, 104-120, doi:10.1175/2008WAF2007111.1.

Case, J. L., S. V. Kumar, J. Srikishen, and G. J. Jedlovec, 2011: Improving numerical weather predictions of summertime precipitation over the southeastern United States through a high-resolution initialization of the surface state. Wea. Forecasting, 26, 785-807, doi:10.1175/2011WAF2222455.1.

Changnon, S. A., 2003: Characteristics of ice storms in the United Sates. J. Appl. Meteor., 42, 630-639, doi:10.1175/ 1520-0450(2003)042<0630:COISIT >2.0.CO;2.

— freezing rain in the contiguous United States. J. Appl. Meteor., 42, 1302-1316, doi:10.1175/1520-0450(2003)042<1302: TASVOF $>2.0 . \mathrm{CO} ; 2$.

Chelton, D. B., and F. J. Wentz, 2005: Global microwave satellite observations of sea surface temperature for numerical weather prediction and climate research. Bull. Amer. Meteor. Soc., 86, 1097-1115, doi:10.1175/BAMS-86-8-1097.

Cortinas, J. V., Jr., B. C. Bernstein, C. C. Robbins, and J. W. Strapp, 2004: An analysis of freezing rain, freezing drizzle, and ice pellets across the United States and Canada: 1976-90. Wea. Forecasting, 19, 377-390, doi:10.1175/1520-0434(2004)019<0377: AAOFRF $>2.0 . \mathrm{CO} ; 2$.

Courmou, D., and S. Rahmstorf, 2012: A decade of weather extremes. Nat. Climate Change, 2, 491-496.

Deser, C., A. Phillips, V. Bourdette, and T. Haiyan, 2012: Uncertainty in climate change projections: The role of internal variability. Climate Dyn., 38, 527-546, doi:10.1007/ s00382-010-0977-x.

Fuhrmann, C. M., 2011: A trajectory approach to analyzing the ingredients associated with heavy winter storms in central North Carolina. Ph.D. dissertation, University of North Carolina, $220 \mathrm{pp}$.

-, and C. E. Konrad II, 2013: A trajectory approach to analyzing the ingredients associated with heavy winter storms in central North Carolina. Wea. Forecasting, 28, 647-667, doi:10.1175/ WAF-D-12-00079.1.

Gao, Y., T. Wu, B. Chen, J. Wang, and Y. Liu, 2013: A numerical simulation of microphysical structure of cloud associated with the 2008 winter freezing rain over southern China. J. Meteor. Soc. Japan, 91, 101-117, doi:10.2151/jmsj.2013-202.

Graff, L. S., and J. H. LaCasce, 2014: Changes in cyclone characteristics in response to modified SSTs. J. Climate, 27, 42734296, doi:10.1175/JCLI-D-13-00353.1.

Grout, T., H. Yang, J. Basara, B. Balasundaram, Z. Kong, and T. S. Bukkapatnam, 2012: Significant winter weather events and associated socioeconomic impacts (federal aid expenditures) across
Oklahoma: 2000-10. Wea. Climate Soc., 4, 48-58, doi:10.1175/ WCAS-D-11-00057.1.

Gyakum, J. R., and P. J. Roebber, 2001: The 1998 ice stormAnalysis of a planetary-scale event. Mon. Wea. Rev., 129, 2983-2997, doi:10.1175/1520-0493(2001)129<2983: TISAOA $>2.0 . \mathrm{CO} ; 2$.

Holloway, B. S., 2007: The role of the Great Lakes in northwest flow snowfall events in the southern Appalachian Mountains. M.S. thesis, Dept. of Marine, Earth and Atmospheric Sciences, North Carolina State University, 204 pp. [Available online at http://www.lib.ncsu.edu/resolver/1840.16/1202.]

Hong, S. Y., J. Ock, and J. Lim, 2006: The WRF single moment 6-class microphysics scheme (WSM6). J. Korean Meteor. Soc., 42, 129-151.

Hosek, J., P. Musilek, E. Lozowski, and P. Pytlak, 2011: Forecasting severe ice storms using numerical weather prediction: The March 2010 Newfoundland event. Nat. Hazards Earth Syst. Sci., 11, 587-595, doi:10.5194/nhess-11-587-2011.

IPCC, 2013: Climate Change 2013: The Physical Science Basis. Cambridge University Press, 1535 pp., doi:10.1017/ CBO9781107415324.

Johnson, H. L., and C. E. Duchon, 1995: Atlas of Oklahoma Climate. University of Oklahoma Press, $104 \mathrm{pp}$.

Kain, J. S., S. M. Goss, and M. E. Baldwin, 2000: The melting effect as a factor in precipitation-type forecasting. Wea. Forecasting, 15, 700-714, doi:10.1175/1520-0434(2000)015<0700: TMEAAF $>2.0 . \mathrm{CO} ; 2$.

Kara, A. B., and C. N. Barron, 2007: Fine-resolution satellite-based daily sea surface temperatures over the global ocean. J. Geophys. Res., 112, C05041, doi:10.1029/2006JC004021.

Kunkel, K. E., and Coauthors, 2013: Monitoring and understanding trends in extreme storms: State of knowledge. Bull. Amer. Meteor. Soc., 94, 499-514, doi:10.1175/ BAMS-D-11-00262.1.

Lackmann, G., 2011a: Improving understanding and prediction of warm season precipitation systems in the southeastern and mid-Atlantic regions. North Carolina State University Dept. of Marine, Earth, \& Atmospheric Sciences Final Rep., 36 pp. [Available online at http://www.erh.noaa.gov/rah/science/ NCSU_CSTAR_III_Final_Report.pdf.]

_ 2011b: Midlatitude Synoptic Meteorology: Dynamics, Analysis, and Forecasting. Amer. Meteor. Soc., 345 pp.

Lebeaupin, C., V. Ducrocq, and H. Giordani, 2006: Sensitivity of torrential rain events to sea surface temperature based on high-resolution numerical forecasts. J. Geophys. Res., 111, D12110, doi:10.1029/2005JD006541.

Lindzen, R. S., and B. Farrell, 1980: A simple approximate result for the growth rate of baroclinic instabilities. J. Atmos. Sci., 37, 1648-1654 doi:10.1175/1520-0469(1980)037<1648:ASARFT>2.0.CO;2.

McPherson, R. A., and Coauthors, 2007: Statewide monitoring of the mesoscale environment: A technical update on the Oklahoma Mesonet. J. Atmos. Oceanic Technol., 24, 301-321, doi:10.1175/JTECH1976.1.

Mellor, G. L., and T. Yamada, 1982: Development of a turbulence closure model for geophysical fluid problems. Rev. Geophys. Space Phys., 20, 851-875, doi:10.1029/RG020i004p00851.

Mesinger, F., and Coauthors, 2006: North American Regional Reanalysis. Bull. Amer. Meteor. Soc., 87, 343-360, doi:10.1175/ BAMS-87-3-343.

Milbrandt, J. A., and M. K. Yau, 2005: A multimoment bulk microphysics parameterization. Part I: Analysis of the role of the spectral shape parameter. J. Atmos. Sci., 62, 3051-3064, doi:10.1175/JAS3534.1. 
— and - 2006a: A multimoment bulk physics parameterization. Part III: Control simulation of a hailstorm. J. Atmos. Sci., 63, 3114-3136, doi:10.1175/JAS3816.1.

— zation. Part IV: Sensitivity experiments. J. Atmos. Sci., 63, 3137-3159, doi:10.1175/JAS3817.1.

— _ _ - J. Mailhot, S. Belair, and R. McTaggart-Cowan, 2010: Simulation of an orographic precipitation event during IMPROVE-2. Part II: Sensitivity to the number of moments in the bulk microphysics scheme. Mon. Wea. Rev., 138, 625-642, doi:10.1175/2009MWR3121.1.

_ - J. Thériault, and R. Mo, 2014: Modeling the phase transition associated with melting snow in a 1D kinematic framework: sensitivity to the microphysics. Pure Appl. Geophys., 171, 303 322, doi:10.1007/s00024-012-0552-y.

Miller, D. K., 2012: Near-term effects of the lower atmosphere in simulated northwest flow snowfall forced over the southern Appalachians. Wea. Forecasting, 27, 1198-1216, doi:10.1175/ WAF-D-11-00103.1.

Mullens, E. D., 2014: Moisture and thermal characteristics of Southern Plains ice storms: Insights from a regional synoptic climatology and high-resolution WRF-ARW sensitivity study. Ph.D. dissertation, University of Oklahoma, $342 \mathrm{pp}$.

NCEP, 2000a: NCEP/CPC four kilometer precipitation set, gauge and radar (updated quarterly). U.S. Dept. Commerce/NOAA/ NWS/National Centers for Environmental Prediction/Climate Prediction Center and University Corporation for Atmospheric Research Joint Office for Science Support, Research Data Archive at the National Center for Atmospheric Research Computational and Information Systems Laboratory, accessed September 2013. [Available online at http://rda.ucar. $\mathrm{edu} / \mathrm{datasets/ds507.5.]}$

_ 2 2000b: NCEP FNL operational model global tropospheric analyses, continuing from July 1999 (updated daily). U.S. Dept. Commerce/NOAA/NWS/National Centers for Environmental Prediction, Research Data Archive at the National Center for Atmospheric Research Computational and Information Systems Laboratory, accessed May 2013, doi:10.5065/ D6M043C6.

Oklahoma Department of Emergency Management, 2010: 2010 annual report. Oklahoma Dept. of Emergency Management Rep., 15 pp. [Available online at https://www.ok.gov/OEM/ documents/Annual\%20Report\%20-\%2016\%20pgs.pdf.]

Ramos da Silva, R., G. Bohrer, D. Werth, M. J. Otte, and R. Avissar, 2006: Sensitivity of ice storms in the southeastern United States to Atlantic SST-Insights from a case study of the December 2002 storm. Mon. Wea. Rev., 134, 1454-1464, doi:10.1175/MWR3127.1.

Ressler, G. M., S. M. Milrad, E. H. Atallah, and J. R. Gyakum, 2012: Synoptic-scale analysis of freezing rain events in Montreal, Quebec, Canada. Wea. Forecasting, 27, 362-378, doi:10.1175/WAF-D-11-00071.1.

Reynolds, R. W., T. M. Smith, C. Liu, D. B. Chelton, K. S. Casey, and M. G. Schlax, 2007: Daily high-resolution blended analyses for sea surface temperature. J. Climate, 20, 5473-5496, doi:10.1175/2007JCLI1824.1.

Robbins, C., and J. V. Cortinas Jr., 2002: Local and synoptic environments associated with freezing rain in the contiguous
United States. Wea. Forecasting, 17, 47-65, doi:10.1175/ 1520-0434(2002)017<0047:LASEAW>2.0.CO;2.

Sanders, K. J., C. M. Gravelle, J. P. Gagen, and C. E. Graves, 2013: Characteristics of major ice storms in the central United States. J. Oper. Meteor., 1, 100-113, doi:10.15191/nwajom.2013.0110.

Semmler, T., S. Varghese, R. McGrath, P. Nolan, S. Wang, P. Lynch, and C. O'Dowd, 2008: Regional model simulation of North Atlantic cyclones: Present climate and idealized response to increased sea surface temperature. J. Geophys. Res., 113, D02107, doi:10.1029/2006JD008213.

Shi, J. J., and Coauthors, 2010: WRF simulations of the 2022 January 2007 snow events over eastern Canada: Comparison with in situ and satellite observations. J. Appl. Meteor. Climatol., 49, 2246-2266, doi:10.1175/2010JAMC2282.1.

Shin, H. H., and S.-Y. Hong, 2011: Intercomparison of planetary boundary layer parameterizations in the WRF Model for a single day from CASES-99. Bound.-Layer Meteor., 139, 261281, doi:10.1007/s10546-010-9583-z.

Skamarock, W. C., and Coauthors, 2008: A description of the Advanced Research WRF version 3. National Center for Atmospheric Research Tech. Note NCAR/TN-475+STR, 113 pp. [Available online at http://www2.mmm.ucar.edu/wrf/ users/docs/arw_v3.pdf.]

Stensrud, D. J., 1996: Importance of low-level jets to climate: A review. J. Climate, 9, 1698-1711, doi:10.1175/1520-0442(1996)009<1698: IOLLJT>2.0.CO;2.

Stewart, R. E., and P. King, 1987: Freezing precipitation in winter storms. Mon. Wea. Rev., 115, 1270-1279, doi:10.1175/ 1520-0493(1987)115<1270:FPIWS > 2.0.CO;2.

Thompson, G., P. R. Field, M. Rasmussen, and K. Manning, 2004: Explicit forecasts of winter precipitation using an improved bulk microphysics scheme. Part I: Description and sensitivity analysis. Mon. Wea. Rev., 132, 519-542, doi:10.1175/ 1520-0493(2004)132<0519:EFOWPU>2.0.CO;2.

Thompson, W. T., and S. D. Burk, 1993: Postfrontal boundarylayer modification over the western Gulf of Mexico during GUFMEX. J. Appl. Meteor., 32, 1521-1537, doi:10.1175/ 1520-0450(1993)032<1521:PBLMOT>2.0.CO;2.

Trenberth, K. E., 2012: Framing the way to relate climate extremes to climate change. Climatic Change, 115, 283-290, doi:10.1007/ s10584-012-0441-5.

Vavrus, S., J. E. Walsh, W. L. Chapman, and D. Portis, 2006: The behavior of extreme cold air outbreaks under greenhouse warming. Int. J. Climatol., 26,1133-1147, doi:10.1002/joc.1301.

Wang, H., E. Yu, and S. Yang, 2011: An exceptionally heavy snowfall in northeast China: Large-scale circulation anomalies and hindcast of the NCAR-WRF Model. Meteor. Atmos. Phys., 113, 11-25, doi:10.1007/s00703-011-0147-7.

Xie, S., and Coauthors, 2010: Clouds and more: ARM Climate Modeling Best Estimate data. Bull. Amer. Meteor. Soc., 91, 13-20, doi:10.1175/2009BAMS2891.1.

Xie, S.-P., C. Deser, G. A. Vecchi, M. Jian, T. Haiyan, and A. T. Wittenberg, 2010: Global warming pattern formation: Sea surface temperature and rainfall. J. Climate, 23, 966-986, doi:10.1175/2009JCLI3329.1.

Zerr, R. J., 1997: Freezing rain: An observational and theoretical study. J. Appl. Meteor., 36, 1647-1661, doi:10.1175/ 1520-0450(1997)036<1647:FRAOAT > 2.0.CO;2. 